\title{
Research and Development Plans for Disposal of High-Level and Transuranic Wastes
}

J. W. Bartlett and A. M. Platt Principal Authors

September 1978

On January 19, 1975, research and development programs of the U.S. Atomic Energy Commission (AEC) became part of the newly formed Energy Research and Development Administration (ERDA). In this report, since it refers to work done in 1974 , most references are to AEC programs.

Pacific Northwest Laboratory Operated for the U.S. Department of Energy by 


\title{
NOTICE
}

This report was prepared as an account of work sponsored by the United States Government. Neither the United States nor the Department of Energy, nor any of their employees, nor any of their contractors, subcontractors, or their employees, makes any warranty, express or implied, or assumes any legal liability or responsibility for the accuracy, completeness or usefulness of any information, apparatus, product or process disclosed, or represents that its use would not infringe privately owned rights.

The views, opinions and conclusions contained in this report are those of the contractor and do not necessarily represent those of the United States Government or the United States Department of Energy.

\author{
PACIFIC NORTHWEST LABORATORY \\ operated by \\ BATTELLE \\ for the \\ UNITED STATES DEPARTMENT OF ENERGY \\ Under Contract EY-76-C-06-1830
}
Printed in the United States of America Available from
National Technical Information Service
United States Department of Commerce
5285 Port Royal Road
Springfield, Virginia 22151

Price: Printed Copy $\$$

: Microfiche $\$ 3.00$

NTIS

- Pages Selling Price

$\begin{array}{ll}001-025 & \$ 4.00 \\ 026-050 & \$ 4.50 \\ 051-075 & \$ 5.25 \\ 076-100 & \$ 6.00 \\ 101-125 & \$ 6.50 \\ 126-150 & \$ 7.25 \\ 151-175 & \$ 8.00 \\ 176-200 & \$ 9.00 \\ 201-225 & \$ 9.25 \\ 226-250 & \$ 9.50 \\ 251-275 & \$ 10.75 \\ 276-300 & \$ 11.00\end{array}$


DRAFT

RESEARCH AND DEVELOPMENT PLANS FOR DISPOSAL OF HIGH-LEVEL AND TRANSURANIC WASTES

J. W. Bartlett and A. M. Platt Principal Authors

September 1978

Prepared for

the U.S. Department of Energy

under Contract EY-76-C-06-1830

On lanuary 19, 1975, research and development programs of the U.S. Atomic Energy Commission (AEC) became part of the newly formed Energy Research and Development Administration (ERDA). In this report, since it refers to work done in 1974, most references are to AEC programs.

Pacific Northwest Laboratory

Richland, Washington 99352 
FOREWORD

This document was prepared during FY 1975 as a preliminary definition of the waste disposal R\&D program requested during public hearing on WASH-1539. The program was scoped as a modest 20-year activity as opposed to the current high priority effort.

The intent at that time was to subject the draft to peer review both within and without ERDA. This effort was preempted by priority activities to produce ERDA $76-43$.

The document is being released (without revision and peer review) because of potential usefulness to the groups working on a US policy statement on nuclear wastes.

\section{EXECUTIVE SYNOPSIS}

This plan recommends a 20-year, 206 million (1975 \$'s) R\&D program on geologic structures in the contiguous U.S. and on the midplate Pacific seabed with the objective of developing an acceptable method for disposal of commercial high-level and transuranic wastes by 1997 .

No differentiation between high-level and transuranic waste disposal is made in the first 5 years of the program.

A unique application of probability theory to R\&D planning establishes, at a $95 \%$ confidence leve1, that the program objective will be met if at least fifteen generic options and five specific disposal sites are explored in detail and at least two pilot plants are constructed and operated.

A parallel effort on analysis and evaluation maximizes information available for decisions on the acceptability of the disposal techniques.

Based on considerations of technical feasibility, timing and technical risk, the other disposal concepts, e.g., ice sheets, partitioning, transmutation and space disposal cited in BNWL-1900 are not recommended for near future R\&D. 


\section{CONTENTS}

EXECUTIVE SYNOPSIS •

LIST OF FIGURES.

LIST OF TABLES .

1.0 INTRODUCTION

2.0 PROGRAM OBJECTIVE .

3.0 PROGRAM SCOPE

4.0 PROGRAM SUMMARY

4. 1 R\&D Scope

4.1.1 Disposal Sites and Methods.

4.1

4.1.2 Analysis and Evaluations

4.1

4.1

4.2 Work Structure, Milestones, and Schedule.

4.3 Program Costs.

4.8

5.0 R\&D PROGRAM DESCRIPTION

5.1 Terrestrial Geologic Disposal.

5.1 .1 Continental Disposal . . . . . . . . . . 5.1

5.1 .2 Seabed Disposal . . . . . . . . . 5.12

5.1 .3 Waste Forms . . . . . . . . . . 5.29

5.2 Analysis and Evaluations . . . . . . . . . . 5.33

5.2 .1 Background. . . . . . . . . . . . 5.33

5.2 .2 Assessment of Status . . . . . . . . 5.35

5.2.3 Planned R\&D Activities. . . . . . . . 5.35

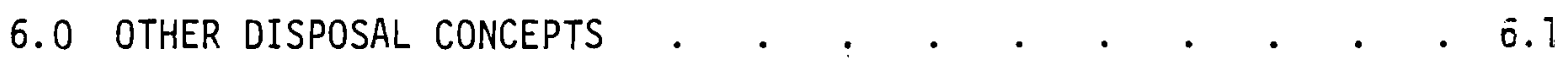

6.1 Disposal to Iced Regions . . . . . . . . . . . 6.1

6.1 .1 Background. . . . . . . . . . . . 6.1

6.1 .2 Assessment of Status . . . . . . . . 6.3

6.2 Partitioning . . . . . . . . . . . . 6.3

6.2 .1 Background. . . . . . . . . . . . 6.3

6.2 .2 Assessment of Status . . . . . . . . . 6.6

6.3 Transmutation. . . . . . . . . . . . . . . 6.9

6.3 .1 Background. . . . . . . . . . . . . 6.9

6.3 .2 Assessment of Status . . . . . . . . 6.10 


\section{CONTENTS (contd)}

6.4 Extraterrestrial Disposal. . . . . . . . . 6.10

6.4.1 Background. . . . . . . . . . . 6.10

6.4 .2 Assessment of Status . . . . . . . . . . 6.11

7.0 PROBABILITY OF PROGRAM SUCCESS. . . . . . . . . . 7.1

7.1 Technical Risk . . . . . . . . . . . 7.1

7.2 Assessment of Technical Risk . . . . . . . . 7.2

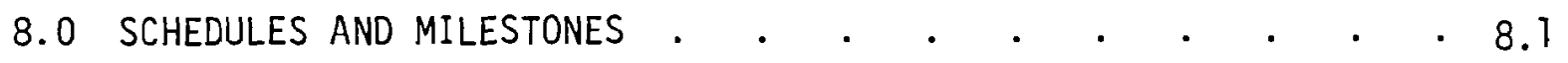

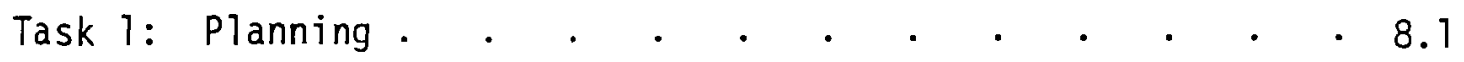

Task 2: Research and Development . . . . . . . . 8.1

\section{LIST OF FIGUIRES}

4.1 Basic Options for Disposal of High-Level Waste 4.3

4.2 Overall Flow of Disposal R\&D Program Activities 4.5

4.3 Use of Analyses and Evaluations 4.6

$\begin{array}{ll}6.1 \text { Development Schedule } & 6.8\end{array}$

8.1 Summary of Schedule and Costs 8.2

\section{LIST OF TABLES}

4. 1 Concepts Under Study for High-Level Radioactive Waste Management

4.2 Anticipated Schedule of Major Activities in the Disposal R\&D Program

4.3 Estimated Program Costs

4.9

6.1 Project Manpower and Cost Schedule 
RESEARCH AND DEVELOPMENT PLANS FOR DISPOSAL OF HIGH-LEVEL

AND TRANSURANIC WASTES

\section{$1.0 \quad$ INTRODUCTION}

When use of a Retrievable Surface Storage Facility (RSSF) as an interim waste management technique was anticipated, it was clearly seen that although it would provide near-term control with proven technology, it had the disadvantage of requiring continued vigilance. Research and development activities aimed at waste disposal which would be safe and not require continued vigilance were therefore accelerated and expanded. However, an explicit statement of the Research and Development (R\&D) activities aimed at disposal has not been made. This report is intended to fulfill that role.

This is expected to be the first of periodic statements of plans for programs on ultimate disposal. These plans will necessarily change as data are obtained, options assessed, and decisions made to reduce the number of options under consideration. At present, revisions are expected to occur at approximately three-year intervals. This schedule may be expanded or contracted, however, as warranted by progress within the program.

\subsection{PROGRAM OBJECTIVE}

The objective for this program is to have accepted methods for terrestrial disposal of commercial high-level and transuranic wastes operational 20 years after this program is authorized.

\subsection{PROGRAM SCOPE}

In keeping with the scope of WASH-1539,* this plan is restricted to R\&O programs aimed at disposal of commercial high-level and transuranic wastes. Other types of commercial wastes and wastes currently stored at the Energy Research Development Administration (ERDA) sites are specificâlly excluded.

* United States Atomic Energy Commission, Management of Commercial High Level and Transuranium-Contaminated Radicactive Waste (Draft), September, 1974. 


\subsection{PROGRAM SUMMARY}

\subsection{R\&D SCOPE}

\subsubsection{Disposal Sites and Methods}

Disposal options previously investigated are listed in Table 4.1. Their relationships to operations within the fuel cycle are shown in Figure 4.1.

Only geologic disposal to the continent or to the seabed is considered viable for attaining operationai disposal of high-level and transuranic wastes 20 years after program inception. As a result of technical assessment of the generic options for geologic disposal, the R\&D on geologic media focuses on:

1. Intrusive igneous rocks such as granite, and crystalline metamorphic rocks such as quartzite, because of their low permeabilities and high mechanical strengths

2. Salt, either in stable domes or thick beds, because of its low permeability and self-sealing properties

3. Tuff and shale because of their low permeabilities and high capacities to retard nuclide migration by adsorption and

4. The midplate/midgyre region of the North Pacific, because of its stability and isolation from man's activities.

Analysis of generic concepts and geoiogic media has been essentially completed by Holifield National Laboratory (HNL), Battelle Pacific Northwest Laboratories (PNL), and Sandia Laboratories. Work on generic systems* and site reconnaissance can be initiated.

\subsubsection{Analys is and Evaluations}

This program includes R\&D to advance capability for assessing feasibility, safety, performance, and impacts associated with disposal system concepts. This work includes:

* Generic System--a complete but conceptual disposal svstem definition including the waste form and any encapsulation, transport system, geologicai media. emplacement technique, and characteristics during the operational mode and monitoring-only disposal phase. 
TABLE 4.1. Concepts Under Study for High-Level

Radioactive Waste Management

A. PROCESSING

Partitioning (a)

B. DISPOSAL ON THE EARTH

Geologic

Mined Cavity

Nuclear Cavity

Deep Hole

Drilled Hole Matrix

Manmade Structures in

Geologic Formations

Hydraulic Fracturing
Seabed

Stable Deep Sea Floor

Subduction Zones and Deep Trenches

Rapid Sedimentation Areas
Ice Sheet

Ice Burial - Free Flow

Ice Burial - Anchored

Ice Surface Facility

C. DISPOSAL OFF THE EARTH

Extraterrestria 1

Solar Impact

Earth Orbit and Solar Escape to Deep Space

\section{ELIMINATION}

Transmutation

Accelerator

Fission Reactor

Nuclear Explosive

Controlled Thermonuclear Reactor

(Fusion Reactor)

a. Partitioning is a chemical separation of waste constituents into two fractions: one which contains the long-lived actinide elements and one which contains the fission products. Variations from this basic definition are also included in the study. 


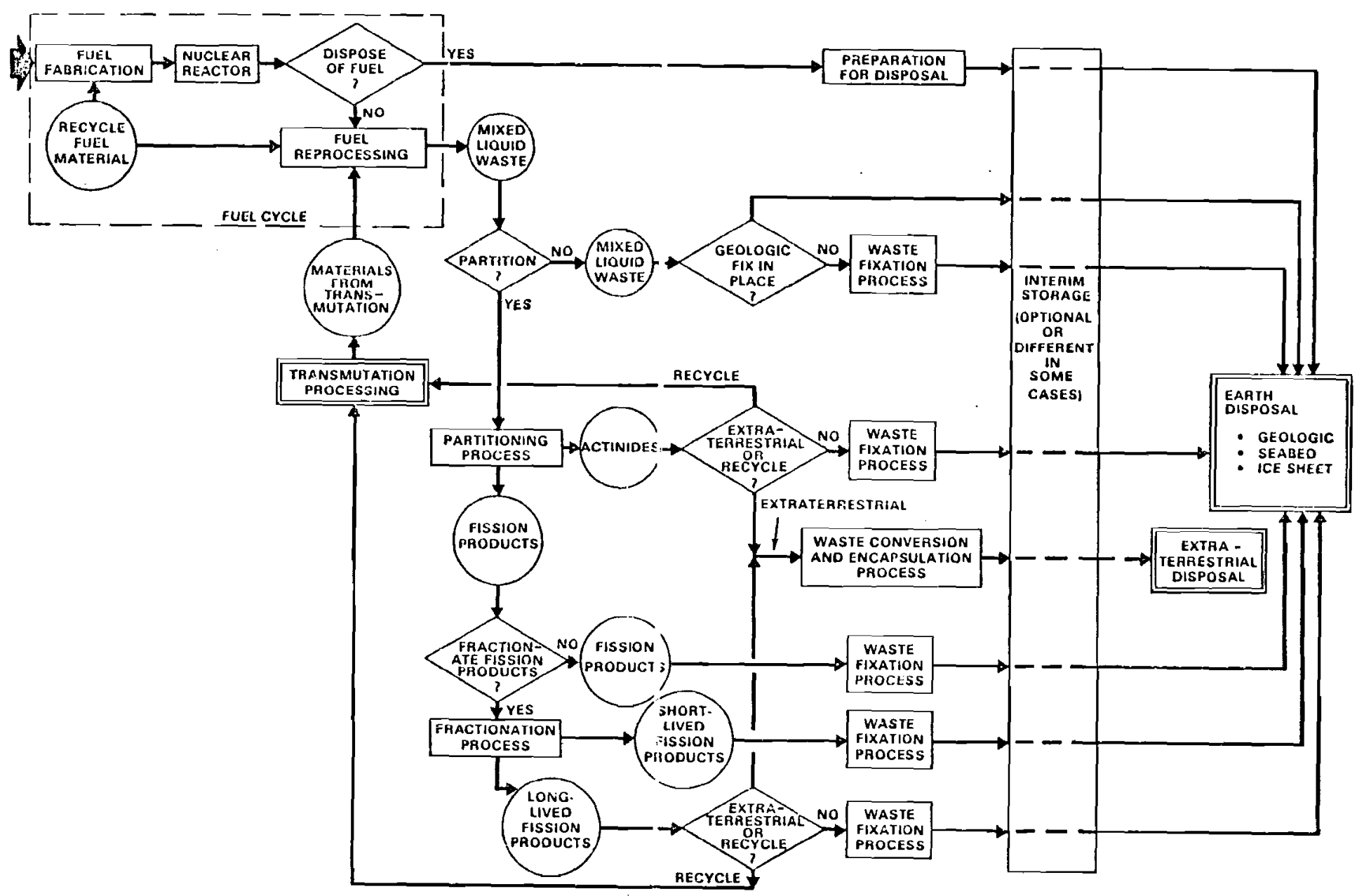

FIGURE 4.1. Basic Options for Disposal of High-Level Waste*

* With changes in source and processing, the same options apply to transuranic waste. Reproduced from BNWL-1900: K. J. Schneider and A. M. Platt, editors and compilers, Advanced Waste Management Studies: High-Level Waste Disposal Alternatives, USAEC Report BNWL-1900, vol. 1-4, Battelle, Pacific Nor thwest Laboratory, Richland, WA, May, 1974. 
1. Improvement and extension of analytical mode1s used to assess safety, and

2. Development and improvement of methods used to assess technical feasibility, system performance as reflected by costs, logistics, and manpower requirements, and implementation impacts including environmental, social (local, national, and international), land use, resources, energy, and economics.

The role of these analyses and evaluations is to provide information and interpretations needed for decisions involving choices among disposal options. Implicit in this function is a responsibility for the program managers to provide support for ERDA's efforts to keep the public aware of program activities, to involve the public appropriately in planning and assessment, and to attempt to secure, when warranted by sound facts, public acceptance as each level of research, development, and assessment is reached. It is the express purpose of this responsibility to provide, with or without request by the public, both the technical data and appropriate interpretation to all interested and affected parties including local, national, and international interests.

\subsection{WORK STRUCTURE, MILESTONES, AND SCHEDULE}

The overall flow of activities in this program is illustrated in Figure 4.2. Applications of analyses and evaluations to the decision process are illustrated by Figure 4.3. As these diagrams show, the program will proceed from the generic to the specific via decisions based on characterization data and concept analysis. Pilot operations will be conducted at sites assessed to meet basic qualifications, and disposal will be implemented at the finally and fully qualified site(s).

Pilot plant operations are expected to qualify and test prior concepts and conclusions. This can be accomplished by use of simulated waste materials, short-lived radioactive materials, or actual waste used in a retrievable mode. Five years of such testing is expected to be necessary. Meanwhile, qualification and licensing procedures for commercial disposal operation could begin. 


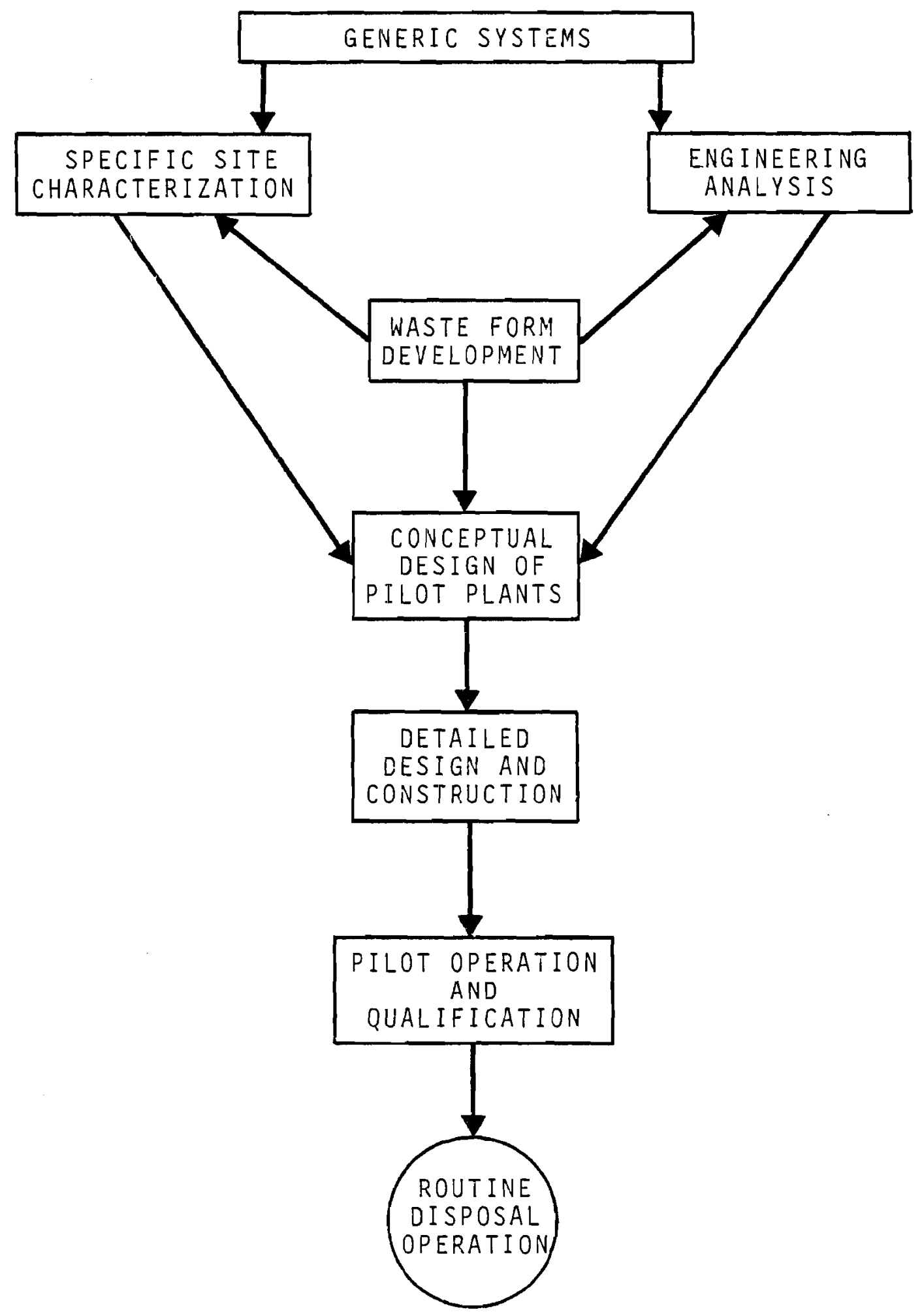

FIGURE 4.2. Overall Flow of Disposal R\&D Program Activities 


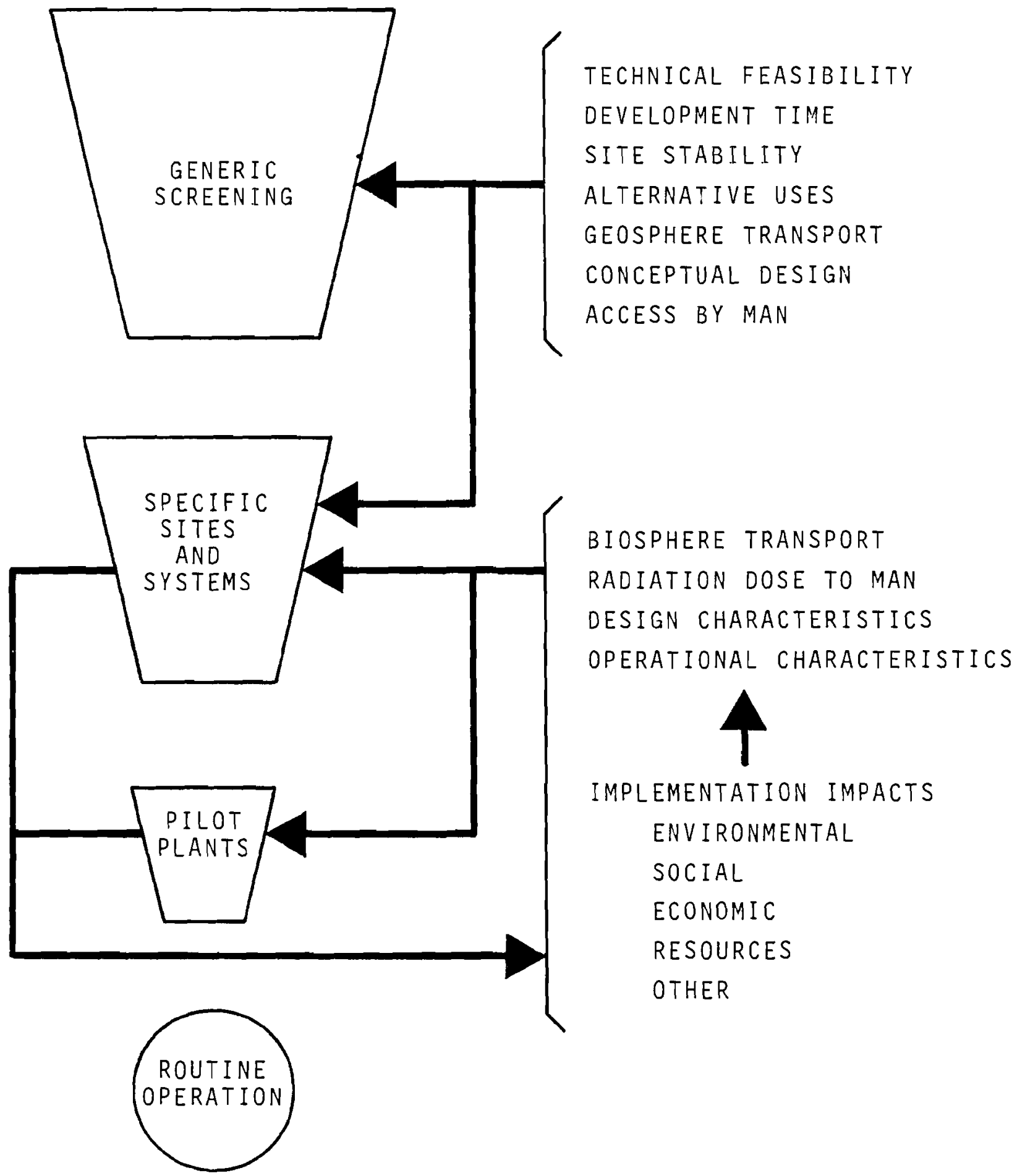

FIGURE 4.3. Use of Analyses and Evaluations 
As described in Section 7, for near-terim planning use an assessment was made of the scope of work needed to assure high probability of attaining acceptable disposal methods within 20 years. On the basis of present knowledge, this study showed:

- Within the four broadly defined generic media for geologic disposal (salt, shale-type and granite-type rocks, and seabed) 15 generic disposal systems (defined as a conceptual system wherein disposal media, waste form, and operations are identified but without detai1) should be chosen and subjected to initial studies. These studies would add data (e.g., by media characterization, design development and evaluation, and impact assessments) sufficient for selection of specific combinations of sites and designs for detailed study.

- The 15 initial studies should be winnowed to five disposal system options for detailed study. These studies would include site reconnaissance and evaluation, further detailing and evaluation of facilities, and assessment of safety, system performance, and implementation impacts. These detailed studies would give bases for decisions to select certain system options for demonstration and verification testing.

- The five specific disposal systems would be winnowed to two (identified by specific sites and operational methods) where five-year verification testing of the pilot plant type will be done. The objective of this testing will be to demonstrate and confirm that the disposal system is acceptable.

The numbers of studies cited here for these three types of effort are based on current uncertainties to be resolved by R\&D and assessments. As study results more sharply characterize the acceptable disposal systems, the number of detailed studies and tests may be fewer than indicated here. Specifically, fewer than five detailed site-system studies may be required, and only one system for testing may be necessary. However, it is essential that the program start with fifteen generic system studies. 
The anticipated schedule for this program is shown in Table 4.2. Selection of the two sites for pilot plant testing should be made late in $\mathrm{CY}$ 1982. At this time scoping design for these operations could also be started. Scoping, detailed design, licensing, and construction of the pilot plant facilities is estimated to require 8 or 9 years. Operation of the pilot facilities is therefore projected to begin in 1992.

TABLE 4.2. Anticipated Schedule of Major Activities in the Disposal R\&D Program

\begin{tabular}{|c|c|}
\hline Activity & $\begin{array}{l}\text { Anticipated } \\
\text { Date } \\
\end{array}$ \\
\hline Detailed Program Plan & $1 / 76$ \\
\hline $\begin{array}{l}\text { Generic Selection Completed and } \\
\text { Specific work on Sites Begun }\end{array}$ & $1 / 78$ \\
\hline Scoping of Pilot Plants Begun & $1 / 83$ \\
\hline Design of Pilot Plants Begun & $1 / 85$ \\
\hline Operation of Pilot Plants Begun & $1 / 92$ \\
\hline Commercial Operation Begun & $1 / 97$ \\
\hline
\end{tabular}

If this schedule is attained, routine disposal operations could be initiated in 1997. At that time, an estimated 50,000 canisters of highlevel waste and $2.4 \times 10^{5}$ cubic meters of transuranic waste would be in Federal custody. Annual production rates at that time are projected to be 5,000 canisters of high-level waste and $3.2 \times 10^{4}$ cubic meters of transuranic waste.

\subsection{PROGRAM COSTS}

A preliminary estimate of costs for this program, developed from prior experience, is shown in Table 4.3. More accurate cost estimates will be possible when the detailed program plan is completed in January of CY 1976. 
TABLE 4.3. Estimated Program Costs

\begin{tabular}{|c|c|c|c|c|c|}
\hline \multirow[b]{2}{*}{$\begin{array}{l}\text { Program } \\
\text { Year } \\
\end{array}$} & \multirow[b]{2}{*}{$\begin{array}{l}\text { Year } \\
\text { (CY) }\end{array}$} & \multirow[b]{2}{*}{ Activities } & \multirow[b]{2}{*}{$\begin{array}{l}\text { Study } \\
\text { Units }\end{array}$} & \multicolumn{2}{|c|}{$1975 \mathrm{M \$}$} \\
\hline & & & & $\begin{array}{l}\text { Unit } \\
\text { Cost } \\
\end{array}$ & $\begin{array}{l}\text { Cost for } \\
\text { Year (a) }\end{array}$ \\
\hline 1 & 76 & Generic Screening & - & - & 5 \\
\hline 2 & 77 & Study Generic Sites & 15 & 0.5 & २ \\
\hline 3 & 78 & $\begin{array}{l}\text { Specific Sites Work } \\
\text { Begun }\end{array}$ & 5 & 2 & 11 \\
\hline 4 & 79 & Specific Sites Work & 5 & 2 & 11 \\
\hline 5 & 80 & Specific Sites Work & 5 & 2 & 11 \\
\hline 6 & 81 & Specific Sites Work & 5 & 2 & 11 \\
\hline 7 & 82 & Specific Sites Work & 5 & 2 & 11 \\
\hline 8 & 83 & $\begin{array}{l}\text { Pilot Plants Scoping } \\
\text { Begun }\end{array}$ & 2 & 3 & 7 \\
\hline 9 & 84 & Pilot Plants Scoping & 2 & 3 & 7 \\
\hline 10 & 85 & $\begin{array}{l}\text { Pilot Plants Design } \\
\text { Begun }\end{array}$ & 2 & 3 & 7 \\
\hline 11 & 86 & Pilot Plants Design & 2 & 3 & 7 \\
\hline 12 & 87 & $\begin{array}{l}\text { Pilot Plant Construc- } \\
\text { tion Begun }\end{array}$ & 2 & 6 & 13 \\
\hline 13 & 88 & $\begin{array}{l}\text { Pilot Plant } \\
\text { Construction }\end{array}$ & 2 & 6 & 13 \\
\hline 14 & 89 & $\begin{array}{l}\text { Pilot Plant } \\
\text { Construction }\end{array}$ & 2 & 6 & 13 \\
\hline 15 & 90 & $\begin{array}{l}\text { Pilot Plant } \\
\text { Construction }\end{array}$ & 2 & 6 & 13 \\
\hline 16 & 91 & $\begin{array}{l}\text { Pilot Plant } \\
\text { Construction }\end{array}$ & 2 & 6 & 13 \\
\hline 17 & 92 & $\begin{array}{l}\text { Pilot Plants Operation } \\
\text { Begun }\end{array}$ & 2 & 4 & 9 \\
\hline 18 & 93 & Pilot Plants Operation & 2 & 4 & 9 \\
\hline 19 & 94 & Pilot Plants Operation & 2 & 4 & 9 \\
\hline 20 & 95 & Pilot Plants Operation & 2 & 4 & 9 \\
\hline 21 & 96 & Pilot Plants Operation & 2 & 4 & 9 \\
\hline & 97 & Commercial Operation & & & \\
\hline
\end{tabular}

a. Each year's cost includes 1.0 M\$ for analysis and evaluations. 


\subsection{R\&D PROGRAM DESCRIPTION}

This section provides details on the background, status, and plans for R\&D expected within this program. Similar discussions of background and status are provided in Section 6 for disposal concepts not to be investigated in this program.

In plans described in this section, no distinction is made between high-level and transuranic waste since both have similar requirements for long-term isolation. Both also have similar feasibility, safety, performance, and impact assessment requirements. However, high-level and transuranic wastes differ in shielding requirements, heat generation rates, and volume. These variations may result in different selections of sites and methods for disposal. All sites are to be investigated and assessed for their suitability for disposal of both types of waste.

\subsection{TERRESTRIAL GEOLOGIC DISPOSAL}

5.1.1 Continental Disposal

\subsubsection{Background}

Continental geologic environments exist which apparently have remained stable, physically and chemically, for millions of years. Because of this stability, disposal of radioactive waste in geologic formations could provide the isolation and containment required until radioactivity has decreased to nonhazardous levels. Both the type of rock material and its geologic setting are primary considerations for potential disposal sites.

BNWL-1900 considered in detail seven basic disposal concepts, with variations such as melting or nonmelting of the waste, and cooling or no cooling after emplacement.

All the potential concepts could operate without partitioning and all would require a means of entry into the formation. Certain concepts would require the forming of cavities within the formation. The final waste form for all concepts is a solid. 
The basic disposal concepts considered in BNWL-1900 were:

1. Solid waste emplaced in a mined cavity

2. Solid waste emplaced in a manmade structure in a mined cavity

3. Liquid waste emplaced in a mined cavity

4. Liquid waste emplaced in an exploded cavity

5. Solid waste emplaced in a matrix of drilled holes

6. Solid or liquid waste emplaced in deep drill holes

7. Liquid waste emplaced by hydrofracturing.

Other work done regarding geologic disposal includes the concept of a Federal Repository, developed by HNL, in which waste canisters would be placed in mined voids in bedded salt deposits, and a study by the United States Geological Survey (USGS) in participation with the Battelle-Northwest study. The USGS study concerned geologic and hydrologic considerations for various waste disposal concepts in the United States. This study was issued by the USGS as Open-File Report 74-158 dated 1974.

A rock type or geologic formation should possess certain characteristics in order to be considered a potential host medium for waste disposal. It should be impermeable or only slightly permeable, massive or free of bedding planes or preferred direction of weakness or fracture, competent enough to support cavity or hole walls, have a relatively high melting point, and be of sufficient thickness to contain and isolate any interaction between the rock and waste.

The geologic setting also should meet certain requirements. It should be a locality where:

1. Seismic risk, or possibility of earthquake damage, is low

2. Flooding from sea-level rise would not affect the site

3. A return of glacial or pluvial climatic conditions would not adversely affect the site

4. Chance of exposure of waste by erosion or denudation is slight

5. Geologic fauliting is nonexistent, of low density or can be characterized as a minor consideration 
6. The site area would be isolated hydrologically from circulating groundwater

7. Economic resources such as hydrocarbon accumulations, 011 shale, metal ores, coal or geothermal prospects are not known to exist

8. Cities, high population density areas and main transportation arteries are not present

9. Surface and topographic conditions are suitable, such as being away from major drainageways and lakes, and in areas of low slope and relief

10. Suitable rock units for the concept can be found at appropriate depths.

Substantial background information exists on specific rock types, as summarized below:

1. Bedded Salt

Information on the general characteristics, advantages and disadvantages, and occurrence of bedded salt deposits in the U.S. is readily available from previously prepared documents. (See, for example, ORNL-CF-73-1-73, ORNL-CF-72-6-42, USGS Open File Report 4339-1, and numerous other reports and papers produced in the course of the previous programs.)

2. Gulf Coast Salt Domes

Preliminary study of the numerous salt domes along the Gulf Coast of the U.S., emphasizing those domes most suitable for future investigation, has been completed (USGS 4339-2, Open File Report, 1973). Also, an independent evaluation of the suitability of salt domes for radioactive waste disposal in general is in progress at the University of Texas (Austin) under the leadership of Dr. R. A. Ripperberger. 


\section{Anticlinal Salt}

Preliminary information on anticlinal or diapiric salt structures in the U.S. has been compiled in USGS Open File Reports 4339-3 and $4339-6$.

4. Excavations at Nevada Test Site

A large number of excavations including shafts, cavities for emplacements of nuclear devices, tunnels, and drill holes have been made in a variety of rock types at the Nevada Test Site. In addition, unique geohydrologic tests already made in many of the excavations would provide rare data on the tightness and stability of rocks such as granite and tuff, especially at great depths.

5. Storage Caverns for Liquid Petroleum Gas (LPG)

During the past two decades more than 80 caverns have been constructed in rocks such as shale, limestone, granite and chalk for storage of petroleum products. These caverns range up to 800,000 barrels capacity and range in depths from 300 to $3000 \mathrm{ft}$ below the land surface. Some have required extensive grouting to provide containment while others are observed to be completely leakproof. Also, roof bolting and other means have been employed to improve stability in some cavities while in others the roofs and pillars have remained intact with little or no artificial support.

6. Existing Dry Excavation in Carbonates

A few existing excavations in carbonate rocks are known to be completely dry and isolated from circulating groundwater. These known examples will be investigated in detail to ascertain which features provide isolation from groundwater and to estimate long-term integrity. The specific cases are:

a. Columbus limestone in Ohio, especially at Barberton mine, Barberton, Ohio. 
b. Selma chalk formation in Alabama, especially at Demopolis.

c. Lansing-Kansas City Limestone at the numerous underground storage chamber in the Kansas city area.

7. Prior Specific Radioactive Waste Projects

From about 1961 to 1971 a concerted effort was made to evaluate the potential for storage and/or disposal of high-level wastes into first crystalline rocks and then Triassic redbeds at the Savannah River Plant. During the 1960 s a search was also made for suitable disposal horizons in the deep volcanic rocks underlying the Hanford reservation. Since these programs generated data directly applicable to this program, it is important that the pertinent findings be incorporated into our studies.

\subsubsection{Assessment of Status}

At present, all continental geologic disposal concepts, with the possible exception of a deep (about $16 \mathrm{~km}$ ) drilled hole, appears capable of implementation with present technology. A $16-\mathrm{km}$ hole could probably be drilled in certain areas, but to routinely drill holes of usable diameter this deep and maintain an open drill hole is still speculative. Mining, drilling and nuclear explosive technology are available for the other hole or cavity forming tasks.

The most suitable rock types for the various concepts are considered to be:

1. Intrusive igneous and metamorphic crystalline rocks, because of their high mechanical strengths and probable low permeabilities, for the deep drilled hole, matrix holes and exploded cavity concepts

2. Salt, tuff and possibly shale for mined cavities and those with manmade structures. Salt has low permeability, high thermal conductivity and natural plasticity. Shale and some varieties of tuff are nearly impermeable and have high ion-exchange capacities. 
Regional areas considered potentially suitable with respect to their geologic setting and for further investigation are:

1. Parts of the stable interior regions where the sedimentary cover is thin or absent

2. The shield area of the north central states

3. The Piedmont metamorphic belt of eastern U.S.

4. Parts of the Basin and Range Province of western U.S., with tuffs and shales above deep water tables and including some granitic stocks

5. Other parts of the U.S. such as the interior and Gulf Coast salt provinces where, for example, stable domes without oil or gas accumulations may be found, or where massive bedded deposits exist.

\subsubsection{Planned R\&D Activities}

5.1.1.3.1 Generic Studies. The geologic and hydrologic generic reconnaissance program is to narrow consideration of a promising rock type from a general region (involving county-size areas or larger) to a single (or at most a few) actual target site(s) and investigate those factors appearing most likely to disqualify the entire disposal system. This will involve evaluation of the potential target sites against a set of specific site selection criteria or factors. For example, see geologic and hydrologic sections of ORNL-TM-4233 for a detailed plan of site investigations for a pilot plant for high-level waste in bedded salt in southeast New Mexico and ORNL-TM-4219 for the specific site selection factors for that proposed facility.

The chief characteristics to be examined for this purpose are those relating to stability (both short-term mechanical stability for operations and long-term tectonic stability for containment of waste) and tightness (that is, isolation from the circulating waters of the biosphere). It is emphasized here that analysis and evaluation of rock types and geologic 
formations for the general case, are of limited usefulness. Characteristics and features of seemingly identical rocks, even of the same formation, vary so greatly from place to place that it is usually necessary to consider a given rock type at a specific locale to gain any meaningful evaluation.

Engineering Assessment of Emplacement Techniques. Preliminary engineering studies are to analyze and assess the technological feasibility of various waste handling and emplacement concepts in general, that is, without reference to their suitability (or lack thereof) in a specific rock type or geologic formation. This assessment will begin with, but not be limited to, those emplacement techniques outlined in BNWL-1900. In general, the work will develop a list of the overall requirements for a waste repository in sufficiently generalized terms to apply to any waste emplacement concept in any rock type. The resulting "criteria" will augment the general geologic and hydrologic studies listed above.

Typical factors to be analyzed include:

1. Access to underground (for data collection, working space and/or for waste handling),

2. Excavation of disposal space and underground operations,

3. Handling and emplacement of waste,

4. Sealing accesses,

5. Techniques for monitoring sealed repository,

6. Rough estimate of scope of research and development program required.

5.1.1.3.2 Specific Sites and Concepts. As noted in the above discussion of generic studies, the suitability of the geologic formation and associated system design concept can be determined only by investigation oi specific sites.

Each promising site and concept will require a separate, and possibly quite different, investigative program, depending on the components of the system, the rock type and locale involved, the quantity and quality of 
of available information, and other factors. However, these programs would probably involve some combination of the following studies:

- Hydraulic Tests in Boreholes. Conduct a series of hydraulic tests in existing or specially drilled boreholes to determine the tightness and/or water-bearing characteristics of the formations of interest.

- Ground and Surface Water Surveys. Determine and define the local and regional water conditions for selected study areas. This would require assembling and interpreting existing data on the areas plus generating any needed supplemental data.

- Surficial Geologic Features. Prepare maps of the surficial geologic conditions at the several study areas. Much of this information would probably be obtained from previous studies. However, some special mapping, including aerial surveys, and geophysical studies may be required to help delineate structural subtleties.

- Subsurface Rock Conditions. Using well logs, cores and other available data, construct cross-sections, isopaths and structural contour maps of the study areas.

- Drilling and Coring. Drill and core at least one hole in each study area. The ensuing well logs and cores will provide key information on subsurface stratigraphy and structure and specimens for determination of various rock properties.

- Mineral Deposits. To preclude conflicts of interest in development of the economic resources of regions considered, the occurrence and nature of mineral deposits must be determined and defined. Make local and regional appraisals of the mineral resources of the study areas and especially of the oil and gas potential and ground water potentials.

- Erosion and Denudation. In extreme cases, natural geologic processes of erosion and denudation have the potential, over 
long geologic periods, to strip away significant quantities of overburden and to subject wastes buried at shallow depths to circulating ground and surface waters.

1. Regional Geomorphology. Based on available knowledge of the geomorphic development of the physiographic provinces of the study areas and of the sediment loads of the major rivers draining these areas, establish the general rates of erosion and denudation.

2. Stream Channeling. Assimilate prior findings on the characteristics of localized Pleistocene channel cuttings and fillings. Project their probable locations and rates of development in the study areas for the next few hundreds of thousands of years.

- Seismicity and Tectonics. Because of the susceptibility to damage of subsurface rock structures as well as surface waste handling facilities during violent earthquakes, areas of tectonic stability and low seismic risk are favored for potential waste repositories.

1. Regional Classifications. Using generalized structural and seismic data that is available for the entire country, determine the classification of the site areas as to tectonic stability and seismic risk.

2. Stabilities of Structures. Plot the epicentral location of all historic earthquakes in the study areas. Then relate their occurrences to the prominent geologic structures (uplifts, basins, faults, folds) to determine the tectonic stabilities of these structural features. Microearthquake studies may also be used to identify localized instabilities.

- Lithologic and Mineralogic Analyses of Rock Cores. Determine and define the rocks and minerals, using analyses of rock cores, at the general horizons of interest for the study areas. 
As a part of the R\&D concerned with all sites, a number of broader and more general experimental and developmental programs will be carried out. Typical of these areas:

- Rock Property Measurement

Develop rock property measurement techniques for rapidly and accurately determining the pertinent mechanical, thermal and chemical properties. This effort is essentially complete (for salt rocks) as a result of prior programs. Techniques and equipment involved will require only minor modification for other rock types.

- Thermal Analysis

Develop and verify thermal analysis codes, procedures and techniques. This effort is aiso essentially complete as a result of prior programs.

- Rock Mechanics Analysis

Develop and verify methods to analyze rock deformation. Again, such efforts have been in progress for salt rocks for some time and are now nearing completion. Several parallel approaches being made involve thermo-viscoelastic and thermoelastic-plastic finite element models and a model based on the face-element technique derived from the Project Salt Vault experimental results. In general, the analysis of deformations for other rocks is much easier than for salt, and these techniques will be directly applicable with only minor modification.

- Borehole Plugging

This program is to develop materials and techniques for emplacing and testing high-integrity borehole plugs and, for salt formations, to thoroughly understand the mechanisms and consequences of a fresh water breach of plug integrity. This information wiil be developed for relatively small diameter drill holes such as are 
routinely drilled for geologic tests and petroleum exploration. That information and experience will also apply directly to the plugging of larger diameter holes such as mine shafts.

5.1.1.3.3 Engineering Analysis of Disposal Concepts. This portion of the program is to refine the general waste handling concept of the disposal concept and site and to carry out the detailed engineering analys is required for a thorough assessment of feasibility. The evaluation of each disposal system will be made by comparison with generalized criteria previously developed.

The following types of studies and analysis are anticipated:

1. Development of a specific "conceptual" design

2. Determination of waste load (i.e., acceptance criteria, total capacity, average and peak delivery rates, etc.)

3. Heat transfer analysis to establish the peak temperatures and temperature distributions resulting from the heat generation of the waste and the thermal transport properties of the geostructure

4. Rock mechanics analysis of the stability of the structure both for the short-term operational period and for the long containment times required to isolate the wastes

5. Analysis of the radiological and chemical compatability of the waste and emplacement technique with the rock materials involved

6. Evaluation of the operational safety of the disposal system

7. Examination of site-related engineering considerations (e.g., power, transportation, population, etc.).

5.1.1.3.4 Pilot Plant Studies. The basic function for pilot plant studies for continental geologic disposal will be to confirm previously established concepts. Pilot studies will not begin until designs and assessments for sites are sufficiently completed to assure a high probability of success. 
Pilot studies can be conducted using surrogates such as short-lived radioisotopes and heating elements. Or a small amount of actual waste material can be used with adequate provision for monitoring and retrieval.

Designs and methods for pilot plant studies will be highly site-specific. Detailed concepts therefore cannot be cited at this time. However, since the major winnowing and assessment procedures will have preceded the pilot studies, conventional design and qualification procedures can be expected for the few sites subject to pilot operations.

\section{1 .2 Seabed Disposal}

\subsubsection{Background}

General requirements for a nuclear waste repository are outlined elsewhere and shall not be repeated here. However, it is useful to base a discussion of the ocean floors on some criteria for area selection. Some basic assumptions include:

1. minimal interference with established resources from the sea;

2. permanent disposal (i.e., recovery is not a criterion); and

3. wastes will contain long-lived transuranic elements.

It is not possible to generalize with regard to ocean regimes. Thus particular places can be found that might otherwise be suitable as repositories but which do not fit general categories. This document shall not inventory the oceans in enough detail to isolate all the sma 11 areas having such characteristics; instead it will be limited to discussion of areas that occur in many parts of the world or that are in some way typical. By this approach, one requirement applied to the ocean regimes is that a candidate disposal area be extensive.

The logistical and engineering requirements for ocean disposal have recently been summarized in BNWL-1900. These are relevant in a discussion of possible candidate areas because engineering and logistics will partly determine the accessibility of each area and the kind of information needed to assess its utility. 
In general, engineering requirements for ocean disposal will include systems for transporting wastes, for emplacing them in the ocean floor, and for containing the wastes once emplaced. Some components of these engineering systems are:

\section{Transportation}

1. Special trucks and casks for land use

2. Special docks as close as possible to reprocessing plants

3. Special ships perhaps

4. Special transfer facilities at the emplacement platform, or use the same ship.

Emplacement

1. Drilling/penetration capabilities

2. Special ship or platform (or neither if transport, drilling, and emplacement can be done with the same vessel).

\section{Containment}

1. A long-lived canister

2. A sealant (artificial or natural) for the hole in the sea floor. While most of the technology for these requirements is either available or within reach, some development will be needed along with proof of the concepts.

The requirements for the natural system--the ocean environments--for selection of candidate areas may be summarized under two generic headings:

- stability and isolation. As will be seen, these imply a large number of individual criteria, but some broad definitions are:

\section{Stability}

1. Lack of cataclysmic events (volcanism and earthquakes)

2. Predictability of processes for necessary times $\left(\leq 10^{6}\right.$ years) 
3. Buffered from effects of climatic changes, glaciations, etc. Isolation

1. Distance from, and unsuitable for, human habitation

2. Low rates of all natural processes (except possibly sedimentation)

3. Longevity of the disposal system.

These characteristics were used to limit discussions to reasonable alternatives.

Within the ocean areas, there are cataclysmic events that could adversely affect any disposal system. Some are indigenous to the ocean environment such as currents, slumping and liquefaction of sediments, erosion by rapid currents, and turbidity. Others are characteristic of the earth at large: earthquakes, volcanism, intrusion by molten igneous rock, and intrusion by man. But there are ocean areas that modern oceanographic data show as particularly stable in respect to these events.

The following discussion focuses on the predictability and rates of natural processes as central concerns. In fact, an understanding of the history of the oceans as they now exist and of global patterns within the ocean system is paramount to a sensible separation of the ocean into a few areas of interest.

Judging from the rate at which information and knowledge in this area is now being developed, it is likely that progress during the next decade will add enough to the body of data that evaluation of seabed disposal concepts can be pursued with increasing confidence.

\section{The Ocean Environment}

While there have been seas throughout the earth's history, the oceans and their floors as they exist today are geologically young: the oldest oceanic rocks recovered from the deep ocean floor are only 155 million years old. Yet it is known that the continents are of the order of 3 to 4 billion years in age, and exposed outcrops of ancient oceanic sediments are of the order of tens to hundreds of miliions of years in age. 
During the past decade, a revolution has occurred in the concept of seafloor evolution. Recently acquired oceanographic data demand, for adequate explanation, that the ocean floors be continually built and destroyed by dynamic processes of crustal movement. This concept, once called continental drift, has been reborn as "plate tectonics." The concept says that the globe is made up of a number of solid rock "plates" composed of oceanic or oceanic-plus-continental crust. These plates are constantly moving in predictable directions and speeds. They are colliding in regions of seismically active deep-sea trenches and in regions of mountain building. Plate boundaries are either areas of crustal destruction where the edges of plates are being thrust under (subducted) or over other plates, or they are areas of construction where, if the earth's diameter is to remain constant, new crust must be made at a rate equal to the destruction rate. Such growth takes place at the center, or rift valley, of the mid-oceanic ridge (MOR), a globe-circling welt about 40,000 km long. At this "spreading center," new molten basalt is constantly being injected into tensional cracks. The sea floor is'spreading here at about 4 to $10 \mathrm{~cm}$ per year.

Volcanism is associated with both the growth and destruction patterns of the plates and perhaps with "hot spots" over which the plates move. From the locations of volcanos and the seamounts (remnants of past volcanos), one can see that only a few areas appear devoid of past volcanic activity.

Within this framework of crustal unrest a description of the principal features of the ocean environment will be made, highighting the characteristics that may apply to long-term disposal.

The importance of biological and chemical processes in assessing the oceanic areas for possible disposal concepts is recognized, and these aspects are included in the R\&D plan. But the discussion here focuses on the geological setting, the frequency of geological events, and the rates of geological processes. No attempt is made to review the basics of marine geology; a standard reference may be used for background information. 
The oceans are divided into three principal physiographic provinces, each occupying about a third of the world's ocean area:

1. Continental margins (continental shelf, inland seas, marginal plateaus, continental slope, continental rises)

2. Ocean basin floor (abyssal plains, abyssal hills, oceanic rises, deep sea trenches)

3. Mid-oceanic ridge (ridge flank and crest, rift valley and rift mountains, fracture zones).

With some obvious exceptions, continental geologic processes are primarily erosional whereas oceanic ones are principally depositional.

The Continental Margin (Shelf, Slope, Inland Seas, Rises)

The continental margin is the most dynamic environment of the ocean. Where seasonal temperature changes in the water are high, chemical and biological processes are most variable, and geology is most complex and unpredictable. Also here lie most of the remaining untapped petroleum and mineral resources as well as most of the world's great fishing grounds.

In these regions the rate of sediment accumulation is rapid, and this, combined with relatively steep slopes, provides optimum conditions for sediment failure (slumping, turbidity currents, etc.). Evidence that these processes occur is abundant.

Ocean Basin Floor (Abyssal Plains, Abyssal Hills, Deep Sea Trenches)

This province, occupying another one-third of the ocean area, is the deepest $(41 / 2$ to $11 \mathrm{~km}$ ) of the three provinces and includes the flat abyssal plains, the gently rolling regions of abyssal hills, and the deepest portion of the oceans--the deep-sea trenches.

The flat abyssal plains (gradients $<1: 1000$ ) are built through deposition by the catastrophic and periodic turbidity currents. These sweep vast quantities of coarse continental debris to this final position by rapid (hundreds of $\mathrm{cm} / \mathrm{sec}$ ) underwater avalanches. Sediments recovered from 
abyssal plains are typically poorly sorted silty clays interbedded with thick, coarsely graded layers of sand and gravel. The temperature of bottom water on these plains does not vary seasonally, and bottom currents are extremely weak and variable.

The abyssal hills that lie seaward of the abyssal plains are originally formed as extrusions of pillow basalt from the mid-oceanic ridge (MOR) spreading center. As the crust spreads away from the MOR, it cools and sinks, reaching a depth of $5 \mathrm{~km}$ beneath the sea in about $50 \mathrm{million}$ years. The vast abyssal-hill province (e.g., most of the North Pacific) is generally covered with 50 to $100 \mathrm{~m}$ of brown clay. The midplate abyssal hills are seismically passive. They are also located centrally in the winddriven, surface-flowing current gyres that are typically quite stable and relatively unproductive biologically. Bottom currents are weak and generally cyclical. For stability the vast $\left(10^{8} \mathrm{~km}^{2}\right)$ regions of the midplate/midgyre abysal hills are unparalleled.

The dynamic deep-sea trenches (70 to $11 \mathrm{~km}$ deep) often form the landward boundaries of abysal hills, especially in the Pacific and Indian Oceans. Here the ocean crust, colliding with and presumably overridden by 1 ighter crustal rock, is being destroyed at a rate of 2 to $4 \mathrm{~cm}$ per year. The arcuate circum-Pacific trenches represent some of the most dynamic regions on the planet. Many high-intensity earthquakes occur in or near trenches. This activity triggers massive submarine slides and is associated with extensive volcanism.

Mid-oceanic rises (e.g., the Bermuda Rise) are broad low swells of abyssal hills generally 4 to $5 \mathrm{~km}$ belo' the surface. Sediment on oceanic rises tends to be thicker than is found on abyssal hills, often exceeding 200 to $500 \mathrm{~m}$.

Mid-Oceanic Ridge

This $40,000 \mathrm{~km}$ long, globe-circling, sea floor spreading center forms the "constructive" plate boundary. In the center of this symmetrical twoway expanding ridge lies the hot, seismically active rift valley (2 to 
$3 \mathrm{~km}$ deep) where new crust is continually extruded. Sediment thickness in this shallowest and youngest part of the ocean is generally too small to be detected except as a thin, current-winnowed veneer of pelagic carbonate seen in photographs of the bottom.

Water temperatures and currents on the shallowest portions of the rift mountains vary markedly in response to wind-driven currents flowing over and around rugged mountainous relief. Bottom water velocities may at times exceed $50 \mathrm{~cm} / \mathrm{sec}$. The temperature of the central portion of the rift valley may approximate that of molten basalt $\left(1200^{\circ} \mathrm{C}\right)$, yet water circulation dissipates this heat so quickly that no water temperature rise can be measured at the sea surface directly above this tremendous $\left(20,000 \mathrm{~km}^{2}\right)$ heat source.

These three provinces comprise the ocean environments chosen for study prior to selecting sites for the detailed investigations described in this R\&D plan.

Seabed Disposal

Because processes are continually changing the morphology of the continents and oceans, and singular events can quickly alter local areas, a chosen site would have to have demonstrated long-term stability. Its history of proven stability would be long enough to assure the safe decay of the radionuclides. The time needed for complete decay, including traces of transuranics, is of the order of a million years.

A comparison of existing data from the major ocean provinces with an eye toward slow processes, freedom from cataclysmic events, and stability over the time scales of interest was made. What becomes apparent is that the most stable places in the oceans, and perhaps on the entire planet, are the midplate/midgyre regions of the major ocean basins. Other attractive features of these regions include the remoteness from human habitation, regional low biological productivity, and low resource potential. of all the oceanic regimes, the least attractive for disposal because of both its high resource potential and the high rates of processes are the continental margins. 
If these tentative conclusions are accepted, the next question is, "Can one conceive of a system that will make use of the great stability of mid-ocean basins for permanent containment of radioactive materials?"

While a straightforward answer is not possible with currently avai1able information, one may make suitable assumptions and at least define the questions that must be addressed to determine the feasibility of such disposal. The technology to transport and emplace materials in the sea floor is available. Finally, it was assumed that the waste material will be solidified, encapsulated, and emplaced well below the sea floor into the bedrock.

The system to be considered, then, includes the encapsulated wastes, the surrounding medium and overlying water column, and the biological community on that bottom and in that water column. Also it includes all the natural processes that occur there plus new ones that may result from the introduction of the wastes and the plug in the hole.

To grasp such a complex system, it is useful to list the possible barriers to a release of radioactivity. (A release is operationally defined to have occurred when the material reaches man or when some administrative controls must be placed upon an area to prevent exposure.) These barriers are:

\section{Generic}

Distance from habitation

Depth of water

Constant conditions (temporal and geographical)

Geologic stability (seismic and sedimentary)

Predictability (lack of cataclysmic events)

Sparse biology

Large dispersal medium (as last resort) 
Stepwise (repository-to-man)

Waste form (solid, nonleachable)

Cask (noncorrodible)

Accretion of chert or manganese oxide on cask

Mel ted medium may solidify into a secondary container

Impervious medium (basalt or sediments)

Heat drives off water, preventing transport

Slow advection through sediments

Sorption or precipitation in sediments

Sediment surface (special chemistry)

Slow currents (tidal only, little or no throughput)

These barriers fall into two loose categories termed "generic" and "stepwise." Those falling in the former class, such as distance from people and relative absence of cataclysmic events, merely describe the setting-conditions to which the engineer can design the system.

The stepwise barriers, listed in more or less the sequence in which they would be encountered, are possible effective preventions for dispersal of radioactive material. For example, several solids have been made from simulated high-level radioactive wastes that have very low solubilities and leaching rates $\left(<10^{-5} \mathrm{~g} / \mathrm{cm}^{2}\right.$ per day $)$. There are a number of cask materials (e.g., nickel, zirconium, titanium) that might have considerable lifetimes in contact with either water or the solid material of the rock and sediments.

Several natural accretionary processes occur in or on the sediments. Manganese and iron oxides precipitate from the water to form manganese nodules on the sediment surface, and amorphous silicates form beds and nodules of chert within the sediments. There is an intriguing possibility that these processes and the melting of the rock itself by heat from the waste could provide added protection by the in situ formation of an 
additional barrier to movement of the radionuclides. Of course, at or near the sediment surface, erosional processes (including biological) could have the opposite effect, and the induced temperature gradient effects will have to be investigated.

Both the basaltic crust of the ocean floor and the overlying sedimentary layers are relatively impervious to the movement of water or materials through them. Beds of amorphous chert could act as a cap to upward migration of pore water containing radionuclides. Water movement upward through the sediments is slow, with rates comparable to those of sediment deposition above it, and the sediments can retard the movement of some elements by sorption processes. The manganese nodules, biological activity on the surface of the sediments, and some early indications from studies of artificial radioisotopes deposited by nuclear testing, all attest to some unknown but interesting processes at or near the sediment/water interface which might immobilize some isotopes.

The final barrier to the isotopes reaching man is, of course, the water column itself. Time scales of thousands of years for transport by the slow bottom currents of a particle of water in the deep basins may not be impossible.

In summary, the rate at which any one of the barriers might be breached could be sufficiently slow to assure isolation. It is these rates, taken together, which will be assessed for each of the important isotopes in the radioactive wastes.

\subsubsection{Assessment of Status}

It is beyond the scope of this plan to detail the amount of available information on many of the processes 1 isted above. Studies to evaluate the seabed's utility for disposal of nuclear wastes have aimed largely at collection of essential data on the natural conditions and processes of the deep sea floor, in particular the midplate/midgyre regions. One description of the requirements of one concept of seabed disposal has been published (BNWL-1900), and the state of our knowledge of the deep seabed has been 
summarized (Bishop and Hollister, Nuclear Tech., December 1974, and Bishop, ed., SLA 73 0596). A set of workshops of involved scientists from many institutions has begun and continues periodically for review and program planning.

Information assessed in FY-1974 has led to three conclusions regarding seabed disposal of transuranic wastes:

1. The state of engineering capability is such that one may with some confidence predict that the needed systems can be developed.

2. Our knowledge is sufficient for selection of the best areas to investigate, namely the midplate/midgyre regions of the deep ocean basins. At this time, it would be unwise to totally eliminate other areas from consideration, and developments of new information will be followed despite no active R\&D by ERDA.

3. All participants agree that no decision on serious development of disposal equipment and facilities should be made until considerable information is amassed regarding candidate areas and a thorough understanding of the effects of the operation is available.

Other organizations such as the National Science Foundation (IDOE, GEOSECS, and Deep Sea Drilling Project), Office of Naval Research, NDAA, and the Bureau of Commercial Fisheries support relevant fundamental research. Information derived from their investigations will continually supplement specific elements of this proposal.

Other countries and international organizations such as NATO, IAEA, and NEA sponsor ongoing oceanographic research. Some of these have interests directly allied with ERDA's. A few of these have been contacted and are both interested in and cooperating with the program. NEA is presently starting an international program for seabed disposal.

The ocean's basin area chosen for detailed study lies in the North Pacific, south of the Aleutian Trench, north of Hawaii, west of the Aleutian Abyssal Plain off Canada, and east of the Emperor seamounts. 
Briefly outlined below is the R\&D program to provide both the needed information base and the development of capabilities for seabed disposal. The participants and managers of the program view such a plan as a changing document constantly under modification as new information is derived and new needs identified and old ones satisfied.

\subsubsection{Planned R\&D Activities}

This section provides a brief description of each of the program elements now included in the program plan. Other elements will be added as they are identified, and some deleted as their objectives are accomplished or as their information is shown to be less relevant.

\subsection{Generic Studies.}

Generic Site Selection. On the basis of the requirements for the disposal system, specific sectors will be chosen for further study and a basis for design of the disposal scheme. A number of such areas will. be identified for further detailed investigation. As information and requirements change, the type of area may also be altered to fit the new requirements.

For reasons noted in the background discussion, these studies are currently focused on the flat abyssal plains. Information that must be collected to narrow this generic site to a specific includes:

- Characteristic Definition

- Geographical

- Geological

- Coarse Survey

- Geophysical Profiling

- Bathymetric Studies

- Macro CTD Data

- Major Currents

- Biological and Sediment Sampling 
- Fine Survey

- Micro CTD Data

- Comprehensive Current Studies

- Detailed Biologic/Sediment Sampling

- Geological Sampling and Analysis

- Mineralogy

- Chemical Analysis

- Feasibility Study for Post-Emplacement Monitoring

- Resource Inventory

Generic Concept. Throughout the program, and particularly during the initial stages, a design concept for the disposal system will be required to provide the focus for the R\&D efforts and to provide the basis for the next steps in the design sequence. This will involve the inventory of all system elements and the arrangement of these elements into a concept most likely to provide operational capability. Periodic revision of the concept on the basis of information from other program elements is the central task of this element.

The two principal concepts currently under study include emplacement in the seabed by drilling and self-emplacement by a penetrometer (missile-shaped canister).

\subsection{Specific Sites and Concepts.}

Specific Site Selection. The selection of specific sites will occur at two times--1) selection of specific sites for detailed study of important information on characteristics of generic sites, and 2) selection of specific candidate sites for disposal operations. The latter will occur only late in the program after intermediate objectives discussed above are reached. The processes, however, will be similar in that information about the types of sites will be translated into selection of the best geographical areas for detailed study. 
Site Characterization. The ocean areas of most promise as candidates for waste disposal are those which have been of little interest to the scientists in the past. Thus one of the most important aspects of the total plan is characterization of the natural setting and processes. Early in the program these comprise the single most important study, and they encompass the entire set of oceanographic disciplines. Focus and direction plus the setting of priorities and information needs come, however, from design and engineering. Simi iarly, information from the site characterization studies exerts strong influences on the nature of the possible disposal systems.

Studies of the specific site include:

- Characterize Geologic Media (Basalt and Sediments)

- Geographic Distributions

- Physical Properties (e.g., composition and texture)

- Chemical Properties (e.g., reactions such as sorption)

- Permeability (natural and forced)

- Effect of heat

- Engineering Characteristics

- Boundary Layer

- Solution/Sediment Interaction

- Gradients of Physical and Chemical Properties

- Deposition, Consolidation and Stability of Seabed

- Organism/Sediment Relationships

- Water Column Dynamics

- Currents

- Diffusion

- Internal Structures

- Biological Community

- Community Structure and Extent

- Species Mobility

- Rates of Biological Processes and Transport 
System Design. A detailed concept which does not include actual hardware specification but which does include specification of operational and facility requirements for the disposal operation is a complement of site characterization. Major elements to be considered include:

Operational Procedures. This element will describe, in enough detail for the conceptual design, all of the operational procedures involved in the disposal scheme, including such things as handling, transportation, emplacement, shielding, personnel safety, etc.

Facilities and Equipment. All elements of the facilities and the required equipment (e.g., ships and handling or manipulation gear) to meet the operational needs of the disposal system will be described in enough detail to allow the conceptual design.

It is expected that efforts on the specific disposal concept will result in additional R\&D efforts. Some typical items include:

- Chemical Effects (at P, T, and with Radiation)

- Accretion (of $\mathrm{MnO}_{2}$, chert, etc.)

- Corrosion

- Leaching

- Compatibility of Materials

- Thermal Effects

- Rock Melting (convection, high temperature chemistry)

- Local Drying Due to Heat Generation

- Material Transport or Convection Due to Heat Generation

- Biological Effects

- Degradation of Emplaced Waste/Canister

- Enhanced Productivity

- Microbiological Activity on or Due to Cask

- Mechanical Disturbance by Macrofauna

- Systems Modeling 
5.1.2.3.3 Engineering Development. Neither a11 of the equipment for the disposal operation nor all of the instrumentation needed for the preliminary studies are available today. It is the responsibility of this program element to design and deliver appropriate hardware and systems for both the studies and ultimately for the disposal system. Thus, this is a supportive element for all of the above sections. In addition, this element will derive essential information from work on site characterization and waste forms and effects. Feasibility of engineering systems to be a part of the disposal operation will be determined in this program element. Requirements are described in the section below on pilot studies.

5.1.2.3.4 Pilot Plant Studies. A pilot plant program for seabed disposal differs substantially from continental "dry" land disposal because of transport and emplacement involving the sea. Factors to be investigated include:

Transportation. It is most unlikely that a reprocessing plant will ever be placed above the parts of the deep seabed presently considered in this program. This calls for development of appropriate transport systems for wastes across both land and water. Within this program element a11 systems for handing the wastes from the site of origin to final emplacement are considered, including manipulative capability where required.

Land Transportation. Basic land transportation systems are developed or under development in other programs. But interfaces with the sea transport, including possible design modification for compatibility and simplicity of operations, are within the logical needs of the seabed disposal program. This element will maintain cognizance of these interfaces and carry out any needed design.

Transfer Facility. Some special facility for transfer from land transport to a ship wi11 be required. This program element will carry out any engineering functions in design and construction of such a facility. Considerations will include shielding requirements, quality control or special handling facilities, changing of casks if necessary, and attachment of any special gear to the shipment. 
Transport Vessel. A special transport ship will be required, but it is likely to be the same vessel as that used for emplacement. This element will work with other elements to design the vessel with regard to needs for shielding, monitoring, handling, docking, and transfer capabilities.

Platform. A stable platform for drilling and emplacement may be needed for use in deep water with due regard to the handling of radioactive materials. These may be different vessels or the same, and will need to be compatible with all of the requirements for transport to the site and emplacement of the wastes in the seabed. This program element will have the responsibility for design of equipment for these needs and for interfacing with other parts of the system.

Manipulative Capability at Depth. If emplacement of the materials requires drilling or other site preparation, and for the event of a loss of a package, manipulative capability beyond the presently available technology will be required. This element will design and build equipment for these needs.

Medium. This element will completely delineate the engineering properties of the emplacement medium, with due cognizance of the requirements for the engineering of the method as well as the safety factors derived from other elements.

Packaging. This element will specify criteria for the waste material and design of a container to accommodate pressure and corrosion needs. The container will be of a size and shape physically and thermally compatible with both the emplacement system and medium.

Site Preparation. Drilled holes, marked locations, manipulative equipment on the bottom and any other preparations of the site which must precede actual emplacement will be the focus of this element. This may include recovery of resources in advance of disposat.

Emplacement. A number of methods of emplacement of the materials into the seabed have been proposed, including free-fall, self-emplacing penetrometers (missile-shaped canisters); gravity penetrators; and drilling. 
It will be the responsibility of this element to evaluate, select, analyze, design and ultimately build equipment for this part of the disposal system. Special considerations for positioning, and monitoring will be made as required.

Hole Closure. While the sediments in the upper few meters may be plastic enough to close under their own weight in a short time, it is likely that back-filling of deeper holes will be required. Special materials and techniques will be devised for this part of emplacement, using as much as possible proven techniques, but meeting the requirements of efficacy of closure for millenia.

Monitoring after Emplacement. The initial period of the disposal operation will be treated as a "pilot" phase, and while there must be every expectation that no nuclides will be found by any monitoring technique, monitoring will take place the first few years to assure that no oversight is leading to failure of the disposal system. Should any leakage be found, the operation would cease while the commitment of wastes to the area is smal1.

\section{1 .3 Waste Forms}

The objective of this task is to define the characteristics of the various waste types considered so that specific concepts can be evaluated. In general, the type of information for each category of waste will consist of:

1. Isotopic composition and concentration,

2. Treatment techniques (solidification, incineration, etc.),

3. Packaging,

4. External radiation fields,

5. External contamination levels,

6. Sources,

7. Estimated quantities and delivery rates, and

8. Shipping modes. 
The required information is generally available at an adequate level of detail for preliminary purposes from a variety of sources (for example, ORNL-3965).

It is anticipated that specific waste characteristics will affect site and concept selection. For example, the high heat generation rate and high gamma fields of high-level waste and the potentially large volume of transuranic waste may result in different emplacement concepts.

Similarly, some early studies on the transport of nuclides in a variety of rocks may result in the selection of different rock types (sites) for wastes of different durability and isotopic content.

\subsubsection{Waste Forms and Effects}

Two important aspects of the program deal with the waste material itself: namely the nature (characteristics) of the waste and the effects (interactions) of emplacing it into geologic media.

5.1.3.1.1 Waste Characteristics. Characteristics of the wastes are determined by two factors. Largely they are determined by the fuel cycle and reprocessing plus subsequent handling or alteration of the forms. But to optimize the disposal system, these factors must be considered in the total system and some requirements placed on the waste form because of the nature of both the disposal medium and system.

Size of Package. Handling capabilities may dictate package size. Or thermal output may be determined by the effects after emplacement. This program element will maintain cognizance of all such relevant information and specify package size, shape and design.

Leachability of Material. Depending on requirements of the disposal medium and its transport mechanisms, the characteristics of any pore water and the history of the waste in terms of its previous processing, this element will determine both the requirements for nonleachability and the characteristics of the as-received material. 
Canister Materials and Design. Based on corrosion rates and materials compatibility, this element will provide a canister design with the necessary lifetime for emplacement and survival (if needed) for some interval in the disposal medium.

Chemical Composition, Radiation Output, etc. This element will characterize the waste materials in those aspects most likely to cause some environmental impact--chemistry, radiation, and heat.

5.1.3.1.2 Chemical Effects. Emplacement of the waste may lead to chemical effects, with either the natural environment affecting the waste material and cask or the emplaced wastes affecting the natural system. In short, a number of new processes may be started by the presence of wastes in the medium. Identification and measurement of these is the responsibility of this program element. A11 such processes will be measured in the presence of pressure, temperature and radiation fields representative of the real case.

Accretion. Several natural accretionary processes are known to occur in or on the seabed. The most significant of these in the deep oceans are the formation of manganese nodules (mixed manganese and iron oxides) and the formation of chert beds (amorphous silica) within the sediments. The possibility of one of these processes taking place on the cask surface or incorporating waste nuclides in the resultant matrix will be investigated.

Corrosion. Corrosion of candidate long-lived materials as well as rates of corrosion of lesser materials within the sediments will be determined.

Leaching. The leaching or other mobilization processes will be determined for the waste material within the representative environment.

Compatibility. Compatibility of the waste materials with candidate cask materials will be studied in representative environments. Reactions with dry (or dried) emplacement medium without the intervention of water will be investigated. 
5.1.3.1.3 Thermal Effects. The initial thermal output of the emplaced wastes will create unnatural driving forces for many phenomena. These can be merely changes in rates (as in chemical reactions) or actual introduction of a new phenomenon (e.g., convection). These wi11 be identified and studied in this program element.

Chemical Rates. In general, rates of chemical reactions increase with increasing temperature. Identification of key chemical reactions and their sensitivity to temperature will be the responsibility of this program element.

Melting of the Medium. If the thermal output of the emplaced wastes is high enough, the capacity of the medium to carry away the heat will be insufficient to keep the wastes below the melting temperature of the wastes or the surrounding medium. The physical and chemical phenomena which result from such a process will be investigated.

Local Drying. Although material transport due to a heat source in a porous medium is not well understood, there is possibility that the lower density of nearby water will retard movement of water to and from the material.

Convection. Convection driven by the heat source is important in two respects--in the cooling of the cask, and in the movement of material away from the cask. For seabed disposal, these phenomena will be studied in the water, in the sediments and ultimately in the underlying basalt. For continental disposal, they will be studied as appropriate for the disposal medium.

5.1.3.1.4 Biological Effects. The biota provides a driving force for some transport of nuclides and perhaps for fixing of nuclides. It also represents an initial point of impact on the environment by the materials emplaced. Effects both on the biological community and by the community on the materials will be investigated.

Degradation of the Emplaced Waste/Canister. Biological activity due to populations attaching to a canister or due to increased activity caused 
by the cask or its heat output can produce chemical effects on the materials and degradation of the cask. These are to be studied for the populations present in or on the seabed and for continental media.

Enhanced Productivity. It is possible and perhaps even likely that the thermal energy of the emplaced wastes will, even at some depth in the seabed sediments, enhance the rates of biological processes. Based on determination of the nature of biological species in the media, these enhancements will be investigated.

Microbiological Activities. Inorganic materials such as metals and silicates are known to enter into the metabolism of certain microbiological species. The effects of these species (if present in or on the seabed) upon the emplaced materials will be studied.

Mechanical Disturbance by Larger Fauna. Surface layers of the sediments undergo constant disturbance by larger fauna. Disturbance of emplaced wastes (if shallow) or of instrumentation and repository equipment will be evaluated.

\subsection{ANALYSIS AND EVALUATIONS}

This section describes plans for R\&D on analysis and evaluation of disposal options. The objective for this work is to provide methodology for making results of R\&D on disposal options useful to decisions.

\subsubsection{Background}

Implementing disposal method(s) will require a series of decisions involving comparison of options. Choices made at the decision points will be based on assessments of feasibility, safety, performance, and impacts for the options available. These assessments require methodologies that provide characterizations and interpretation essential for the decision makers.

The assessments are currently expected to involve the topics listed below. Their use in the decision process is illustrated by Figure 4.3, Section 4. 
Feasibility

Technical feasibility

Timing of availability

Disposal site stability

Alternative uses of site

(resources, etc.)

Accessibility to man

Safety

Postemplacement phenomena:

waste degradation

geosphere transport

biosphere transport

potential radiation dose to man

Operational system:

processes and facilities

transportation
Performance

Costs

Logistics

Manpower

Implementation Impacts

Environmental

Social

Institutiona 1

Land Use

Resources

Energy

Economic

Demographic

These assessments use two types of tools involving these factors: analytical models and interpretive analysis of data for the disposal system. Analytical models are used to assess safety, and interpretive analysis is used to assess feasibility, performance, and impacts.

Numerous analytical tools that can be applied to radioactive waste disposal have been developed in the past. These include risk analysis, cost-benefit analysis, decision theory, utility theory, and the usual concepts for engineering models of systems and rate processes. To apply these methodologies to disposal will require that specific requirements for analysis and assessment be defined. Recent interactions with representatives of the social sciences indicated that this requirement for specificity extends to assessments of implementation impacts. Thus the scope and content of the analytical tools will depend on the characteristics of the disposal media and sites selected for investigation. 


\subsubsection{Assessment of Status}

Within the usual limitations associated with assurnptions and methods used in evaluations, the basic analytical tools anticipated necessary for this program exist today. In many cases, however, they must be improved and adapted to the needs of this program. Also, application of many of the models is at present data-limited, i.e., the data to be obtained within this program are needed for implementation of the methodology.

Successful development and application of assessment capability will require broad-based peer review of methodology and public review of results. Iterative dialog between the developers of the assessment tools and the users of the results can and should be used to focus R\&D in this sector and to assure that results meet needs.

\subsubsection{Planned R\&D Activities}

Assessment methodology will be developed and applied in the following areas:

\subsubsection{Safety and Performance Analys is}

Throughout the program the designs and the information on performance projections of the repository will be analyzed to assess both operational safety and the projected ability for the system to provide containment of nuclides for the required time. This effort will require both the preparation of exhaustive reports and the application of several techniques for analytical or numerical modeling of the system to predict efficacy. Topics to be covered will include:

Release Rates and Event Probabilities. Given that all processes, including those having adverse effects on the performance of the system, will proceed steadily and inexorably over the times of interest, rates of migration of the nuclides through the containment barriers will be evaluated by modeling the containment system, the mechanisms of nuclide transport, and the consequences of transport in terms of radiation doses and other phenomena in man's environment. The rates of these processes will be compared with the decay of the nuclides. Also, singular events (e.g., earthquakes, volcanism, 
etc.) occur not with steady rates but with estimable probabilities. These will be analyzed in one of the usual probabilistic manners (e.g., "fault tree analysis") and combined with the results of the determination of rates to give a complete picture of the performance of the system for great periods of time. This procedure will permit decisions regarding siting and performance criteria as well as the key decisions on elements of the system (e.g., cask, hole closure, etc.).

Incentives for Partitioning. A study begun in FY-1975 to assess operation of the fuel cycle and waste disposal by removing actinides from highlevel waste ("partitioning") will be completed. See Section 6.2 for a discussion of partitioning.

The incentives study is aimed at determining if development and implementation of partitioning is worthwhile. The question arises because if it can be demonstrated that potential post-disposal rate processes are slow enough to prevent unacceptable return to man's environment, the complications and expense of partitioning would not be necessary.

The present incentives study is focused on determining the long-range benefits that could be obtained if partitioning were used to remove actinides from high-level waste placed in disposal. Basic methodology for the work is to assume events whereby waste can escape the repository and to compare potential radiation doses to man with and without actinides present in the waste.

The present study is not yet complete. Since it addresses only longrange benefit issues and not the near-term tradeoffs of fuel cycle operations, it also is only a first step toward evaluation of partitioning incentives. However, if this study demonstrates that the long-range benefits of partitioning are negligible, it may be the only type of study necessary since partitioning would inevitably add costs and complexity to near-term operations. Determination of whether or not the long-range benefits of partitioning are "significant" may require action beyond the present study, especially if projected benefits are not clear-cut. 
The present study also includes investigation of long-lived fission products such as ${ }^{129} \mathrm{I}$ and ${ }^{99} \mathrm{Tc}$. Preliminary results suggest that these isotopes might also be targets for partitioning-type operations. They have very long half-lives, they are biologically significant, and they are readily transported by water in the geosphere and biosphere.

\subsubsection{Environmental Impacts}

Analys is of the impact of both the disposal operation, and of the site after disposal, on the environment and the local biological community will be made in the usual manner and at the usual junctures in the program.

\subsubsection{Economic Analysis}

Costs of development, construction, operation and shutdown of the entire system will be analyzed at each step of the program. A11 parts of the system, including solidification, encapsulation, handiing and transportation, will be covered in the economic analyses to allow complete cost accounting for the ultimate disposal of the waste.

\subsubsection{Social Impact Analysis}

Impacts on labor force, population location, organizational requirements, and other social commitments to the disposal scheme will be made at the earliest possible junctures in the operation of the development program. Local, national and international issues will be considered.

\subsubsection{Systems Modeling}

Models will be developed for the prediction of rates and processes, for the probabilistic evaluation of singular events, and for the complete evaluation of the performance of the disposal system during and after disposal operations. This will include nuclide transport, destructive and constructive processes, disturbing events, and all other factors related to performance of the system in containment of the radioactive wastes. 


\subsection{OTHER DISPOSAL CONCEPTS}

This section discusses the background and status of disposal concepts not plarned for R\&D within this program. It is not intended that these concepts should be permanently disregarded. Rather, for specific reasons described in each section, it has been decided that, with current technology, expected R\&D costs, timing to operation, and probability of success, extensive work on these concepts is at present unwarranted.

Many other U.S. Federal agencies, international organizations, and other nations have ongoing R\&D programs relevant to these disposal concepts. Present assessment is that major technological breakthroughs would be essential to make these concepts as attractive, in terms of probability of success, as those for which R\&D is planned. Progress in these other programs will be continually monitored. If significant advances occur, work might be activated in these sectors.

\subsection{DISPOSAL TO ICED REGIONS}

\section{- 6.1.1 Background}

BNWL-1900 investigated disposal of solidified high-level waste to regions such as Antarctica or Greenland which have large permanent masses of ice overlying continental land masses. Such regions are currently remote from most human activity and have low likelihood of future development. Ice was considered as a disposal medium because it can self-heal fractures, it has low permeability to water, biological activity is low, and its thermal conductivity is comparable to that of common rocks.

Three potential disposal concepts were investigated, all of which could operate without partitioning and would require transport from point of origin to the iced region:

1. Meltdown or free flow--the waste canister would be placed in an individual shallow drilled hole in the ice and allowed to melt down through the ice sheet to bedrock. 
2. Anchored emplacement--the waste canister would be placed in a shallow drilled hole in the ice and connected to surface anchors by cables or chains, which stop its descent and maintain its position for some extended period, perhaps on the order of 100 years.

3. Surface storage/disposal--the waste canisters would be placed in a shielded cell storage facility with jack-up piers on the ice sheet surface to provide heat removal to the ambient air or to prevent covering over by further ice accumulation. After about 50 years, the facility would be allowed to become covered by accumulating snow and eventually buried in the ice sheet for final disposal.

The operational aspects of these disposal concepts could be implemented with known technology. However, there are at present many urknowns concerning what would happen to the waste after emplacement. In brief, the post-disposal stability of the waste is highly in doubt because of current lack of technical data on behavior and physical properties of ice sheets. Costs of R\&D to obtain needed data are estimated to be very large, and many years of investigation would be needed.

The Scientific Committee on Antarctic Research (SCAR) Working Group on Glaciology had radioactive waste disposal on their agenda for their Cambridge, England meeting on September 23-25, 1974. Their minutes on this topic are reproduced below.

"The last day of the Working Group meeting was devoted to a joint discussion with the IAGP Council and the Officers of ICSI on the disposal of radioactive wastes in the Antarctic ice sheet (Notes on a meeting held at the Scott Polar Research Institute, Cambridge, on September 25, 1974). Fifteen scientists from eight countries attended. The following conclusions were reached:

1. We conclude that the Antarctic Ice Sheet is not a suitable site for the disposal of radioactive wastes that need to be isolated from the biosphere for periods of several hundred thousand years. 
2. Over the last 20 years or so theoretical and observational studies of the Antarctic and Greenland Ice Sheets have allowed us to build up an understanding of the basic physics of ice sheets sufficient to go some way to answering the glaciological questions posed by Or. Zeller's proposal, and by the Battelle Memorial Institute Study.

We consider that, at this stage, the efforts of the glaciological community should continue to be directed towards a better understanding of the basic physics and thermodynamics of ice sheets. Such an understanding is essential before any profitable consideration can be made of applied problems such as those that would be associated with nuclear waste disposal on ice sheets."

\subsubsection{Assessment of Status}

Compared with other concepts for terrestrial disposal, iced regions offer the advantage of present and probably future remoteness from high levels of activity by man. This advantage is offset, however, by the costs and hazards associated with transport to the disposal site.

The greatest disadvantages to iced region disposal, however, are the present comparative lack of information needed to assess post-disposal safety and the extreme costs and duration of time needed to obtain that information. When compared with other concepts for terrestrial disposal, the costs and uncertainties for detailed assessment of the iced regions are too great to justify further action at this time for disposal purposes.

\subsection{PARTITIONING \\ 6.2.1 Background}

High-level radioactive waste generated in nuclear fuels reprocessing plants contains radionuclides having a wide range of half-lives--from less than 100 days to millions of years. Because of the long-lived constituents, 
it and the transuranic wastes, which also contain long-lived actinides, wi11 remain radioactive for times comparable to periods for major geological changes in the earth's crust.

One alternative for managing high-level radioactive waste involves separating or "partitioning" the waste into fractions of different halflives. Short-lived fractions would decay to low levels of radioactivity in about 1000 years, a time period that is geologically insignificant and within man's control. Long-lived fractions--which would have low mass, volume and radioactive decay heat output--could be considered for other treatment, e.g., transmutation to nonradioactive or short-lived nuclides, extraterrestrial disposal, or special terrestrial disposal.

Partitioning will divide the high-level waste into long- and short-lived fractions and thereby allow the two waste fractions to be managed separately. The short-lived, fission product fraction will diminish to very low levels of radioactivity in about a thousand years, and the long-lived fraction, much smaller in quantity and heat generation rate, can be handled by other waste management options. In the broadest sense only three management options exist for the longer-lived actinide fraction of the waste: 1) elimination of the waste constituents by beneficial transmutation (nuclear conversion to other isotopes), 2) safe extraterrestrial transport off the earth, or 3) isolation from man's environment somewhere on earth for time periods long enough to allow natural radioactive decay. These same options are available for transuranic waste.

The short-lived waste fractions will decay to become nonradioactive in relatively short times--times short enough to perhaps consider longterm storage such as in manmade structures. Thus, a disposal method selected specifically for the short-lived fraction might be an option if partitioning is implemented.

To produce a short-lived waste fraction which would decay to insignificant radioactivity levels in about 1000 years would require removal of the actinide elements and perhaps samarium, technetium, tin, iodine, 
and nickel (radioactive nickel is present due to irradiation and dissolution of some fuel cladding) from high-level waste. Very large decontamination factors (ratio of initial concentration in waste to final concentration in waste) in the $10^{6}$ to $10^{8}$ range would be required for some of the elements, particularly the actinides, to render the remainder of the waste materials essentially nonradioactive after about 1000 years' decay time.

If the long-lived elements are to be placed in terrestrial disposal (rather than being transmuted or disposed of extraterrestrially), the waste form and disposal environment should prevent return of the nuclides to man's environment before they have decayed to insignificant levels. Specifically, the waste form should be selected to minimize degradation, and the disposal environment should be selected for characteristics such as low probability of water intrusion or disruptive geologic events, and capability to retain the radionuclides by chemical sorption or similar phenomena. The disposal media may provide retention capability sufficient to eliminate the need for partitioning. It is not yet certain that such capability does or does not exist; this uncertainty is a basis for the "incentives for partitioning" program described in Section 5.2.3.1.

The technical feasibility of partitioning by various means has been investigated as reported in BNWL-1900. These studies indicated that partitioning might be attained by extrapolating current separations technology, but that some major hurdles would have to be overcome. One of the biggest problems is the possibility that suspended solids in process streams would retain the long-lived nuclides so that the separation would not be as effective as needed or designed. Another potential problem is the possibility that the separations process would complicate waste management by proliferating waste streams. Partitioning would also add capital and operating costs to the fuel cycle.

Investigation of such problems has been under way for about the last 2 years. Definitive results are not yet available. However, a comprehensive long-range plan to develop partitioning has been prepared, and a study of incentives for partitioning was begun. 


\subsubsection{Assessment of Status}

The work on partitioning incentives is extremely important because of its leverage with respect to future work on partitioning process development, transmutation, and extraterrestrial disposal. It is also important because it is a springboard for work on evaluation of postdisposal degradation and geosphere and biosphere transport processes. The methodology being developed in this program can, with modifications, be adapted to evaluation of postdisposal phenomena for all media under consideration in this program.

If incentives for partitioning are found compelling, a major longrange program for development will be implemented. Holifield National Laboratory has prepared a comprehensive plan, reported in ORNL-TM-4783, Program for Improved Waste Management in Commercial Nuclear Fuel Reprocessing Facilities, dated January 1975, which can serve as the basis for these activities. The abstract is given below. The manpower and cost schedule and the development schedule given in ORNL-TM-4783 are shown in Table 6.1 and Figure 6.1 , respectively.

PROGRAM FOR IMPROVED WASTE MANAGEMENT IN COMMERCIAL NUCLEAR FUEL REPROCESSING FACILITIES

\section{ABSTRACT*}

The principal objective of the program proposed in this report is to decrease the long-term (>1000 years) hazards of radioactive wastes from commercial nuclear fuel reprocessing facilities. This is to be accomplished by modifying reprocessing methods currently in use to increase actinide recoveries and to produce waste streams that are amenable to recycle or further treatment; all wastes should be treated so as to achieve separation into a solid, fission-product-containing fraction with low concentrations of long-1ived actinides and a semipure concentrated fraction containing the actinides. After sufficient information has been accumulated from laboratory-scale studies to allow preparation of overall, detailed flowsheets and to permit making a technical evaluation, a detailed review will be made to determine if the program should be continued through construction and operation of a large-scale demonstration plant that will satisfactorily treat all waste streams from a modified nuclear fuel reprocessing facility. There is a listing and brief summary of the tasks required to carry out this program. Also included are estimates of the manpower, costs, and time required to complete the program.

* Reproduced from ORNL-TM-4783. 
TABLE 6.1.* Project Manpower and Cost Schedule

(Costa 1n 1974 do1larg)

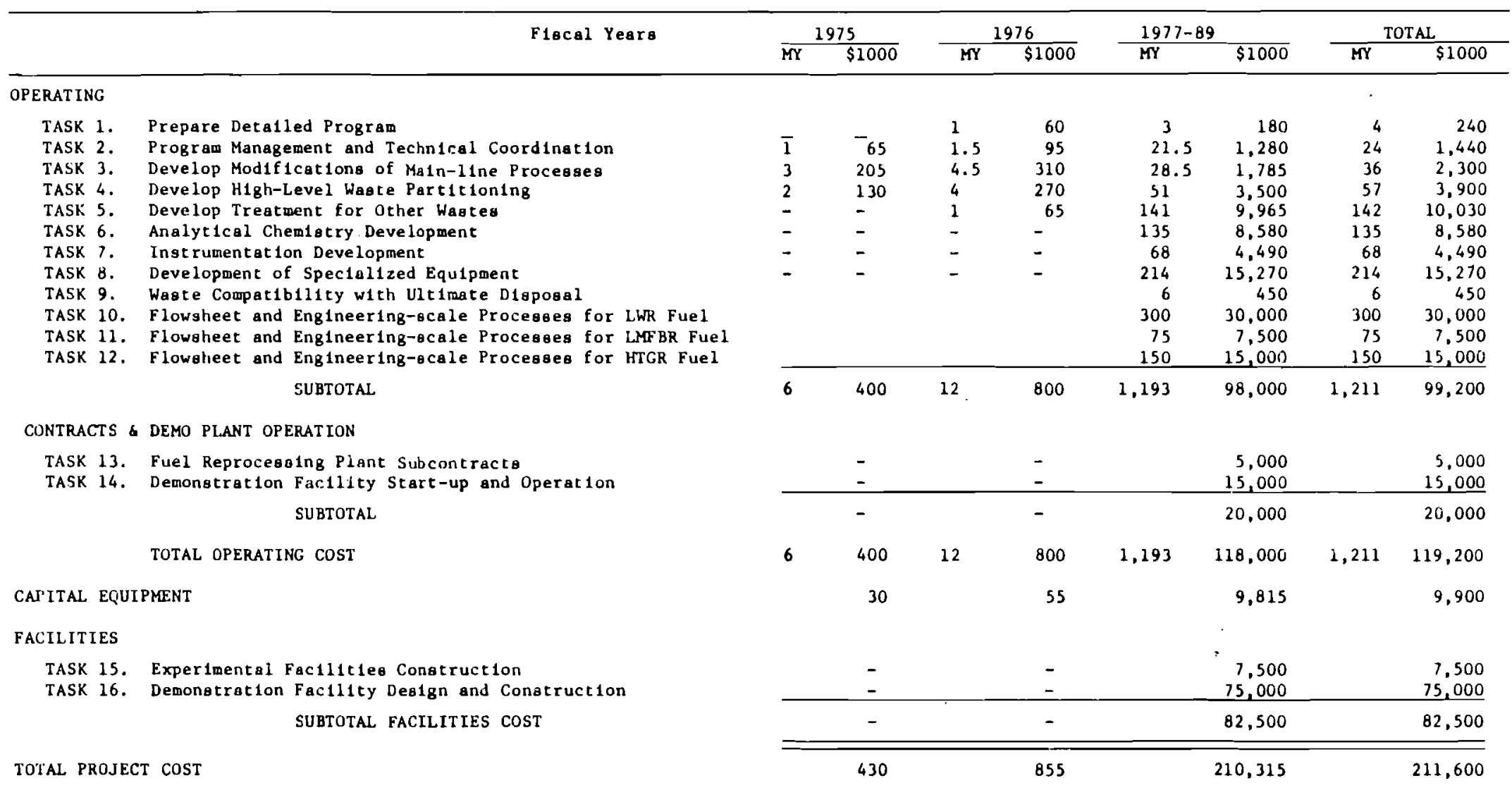

* Reproduced from ORNL-TM-4783. 


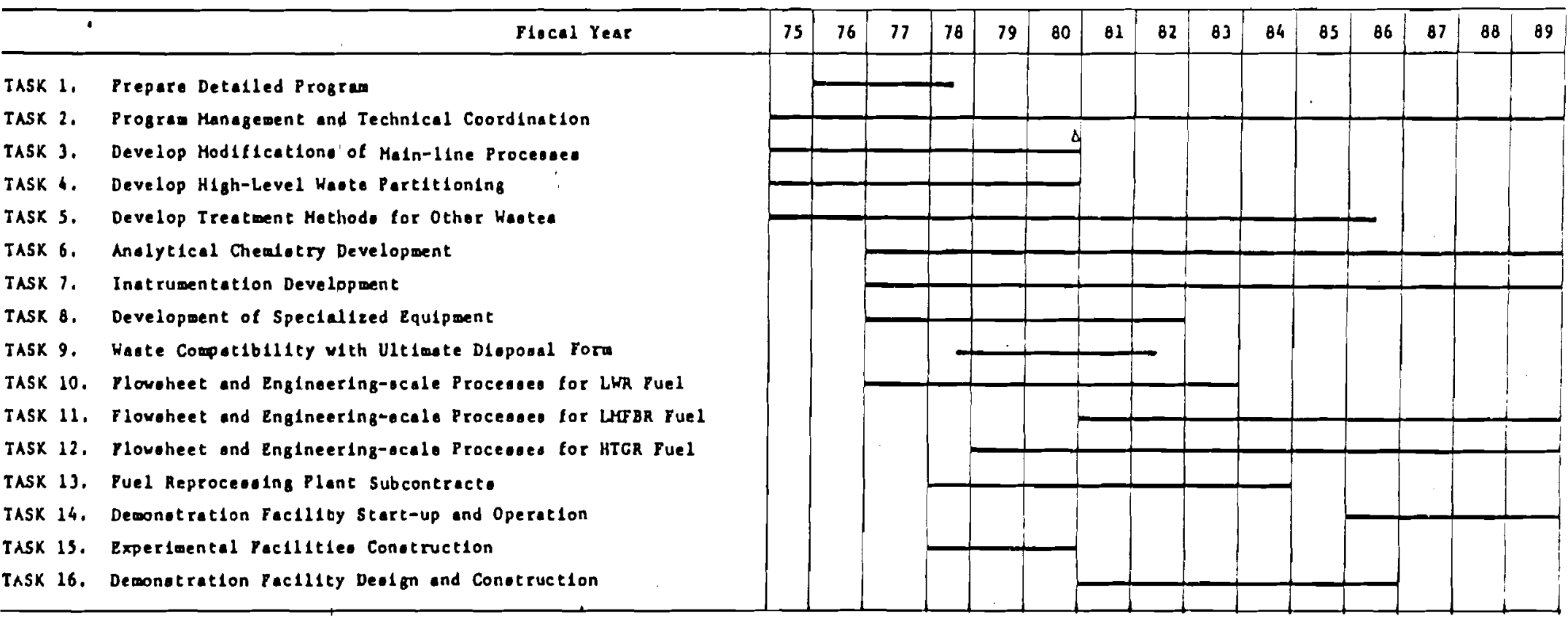

d Review to detarmine if program ahould continue through largo-acalo demonetration.

* Reproduced from ORNL-TM-4783.

FIGURE 6.1.* Development Schedule 


\subsection{TRANSMUTATION}

\subsubsection{Background}

Transmutation changes one isotope into another. For waste management, transmutation should result in a product isotope having a lower toxicity and/ or a shorter half-life than its predecessor. Ideally, radioactive constituents in high-level and transuranic waste could be eliminated by using natural decay to achieve the transmutation. Decay can be accelerated, however, by converting long-lived radioisotopes to other isotopes which have shorter decay times. If this can be achieved, the quantity of longlived radionuclides in waste could be reduced and the time required for decay to negligible levels may be significantly shortened.

The overall waste management system using fission reactors for transmutations of waste actinides requires 1) a period of interim aqueous waste storage to allow for decay and required for partitioning; 2) partitioning of the aqueous waste into an actinide waste steam and a short-lived residue; 3 ) converting the actinides at the reprocessing plant to oxides; 4) transporting the oxide to a facility for fabrication into special recycle fuel forms; and 5) transporting the actinide fuel form to a fission reactor for irradiation. The short-lived fraction must be disposed of by other means.

For the transmutation strategy using fusion reactors, the concept would be similar except that the aqueous waste stream would be partitioned into two or more streams containing waste actinides and possibly selected fission products and a residual waste stream to be disposed of by other methods. The two waste streams for transmutation would be converted into solid fuel materials (probably oxide) at the reprocessing plant. The fuel materials would be transported to a facility for fabrication into special target elements, and the special targets would be transported to and inserted into the blanket of a fusion reactor for irradiation as part of the reactor fuel cycle. Continued recycle of material which undergoes transmutation would also be a part of this operation. 
The waste streams not sent to transmutation must be disposed of by other means. In addition, the "heel" of untransmuted actinide waste at the termination of a nuclear plant era must be disposed of by other means.

As reported in BNWL-1900, the in-reactor transmutation operation appears technically feasible for fission power plants. However, as noted above, a five-step sequence of operations, with partitioning as the key operation, is needed to implement the concept. Thus, practical capability, and incentives, for partitioning are necessary precursors to transmutation.

\subsubsection{Assessment of Status}

Determination that partitioning is essential and feasible should precede work on transmutation. Previous studies have provided a basis for a plan that could be developed and activated if and when the partitioning incentives work indicates it appropriate.

\subsection{EXTRATERRESTRIAL DISPOSAL}

\subsubsection{Background}

If a stable nonearth intercept trajectory or orbit can be assured, extraterrestrial disposal could provide complete renoval of partitioned long-lived nuclear waste constituents from the earth. The primary unfavorable features are that the concept deals with only part of the waste; there are possible launch safety problems; retrievability and monitoring, if necessary, are difficult; and the concept will require international agreements.

In BNWL-1900, extraterrestrial disposal was considered both for a11 waste constituents and for only the transuranic elements. The studies showed that space disposal of only the transuranics could be practical because the space transport cost per unit of weight (at least $\$ 2000 / \mathrm{kg}$ of waste material) would be very high.

A waste management system that uses extraterrestrial disposal would include 1) interim aqueous waste storage to allow for decay and simplification of partitioning; 2) partitioning of the aqueous waste into a 
transuranic element fraction contaminated by no more than $1 \%$ of the fission products and a fission product fraction which must be disposed of by an alternative method; 3 ) conversion of the actinide waste to a refractory oxide and encapsulation into high-integrity, multiple-barrier capsules; 4) transporting the capsules overland to a space launch site; 5) launching the waste into space to an initial low-earth orbit with a reusable space shuttle, followed by space tug transport to the final destination; and 6) monitoring for control to destinations and for off-standard events and radioactivity in the upper atmosphere.

The best destination would be direct solar system escape. About $190 \mathrm{~kg}$ of transuranic waste could be transported in each flight to direct solar system escape with the proposed space vehicles. This capacity provides for disposal of the transuranics from about 280 metric tons of spent LWR fue 1 in each flight.

\subsubsection{Assessment of Status}

Extraterrestrial disposal of the actinides in waste appears technically feasible, but there are many impediments to practical implementation. One of the most crucial is the need for partitioning to isolate the actinides from other waste constituents. Incentives for partitioning have not yet been established.

It is noted, however, that space disposal may be promising for selected wastes, e.g., ${ }^{129}$ I. 


\subsection{PROBABILITY OF PROGRAM SUCCESS}

This section presents a rationale for the projected schedule and scope of work for this program. An analysis of a probabilistic basis for program scope is described.

\subsection{TECHNICAL RISK}

It is the opinion of the authors that a technically acceptable method for safe disposal of nuclear wastes can and will be developed from the list of candidates presented in this document. However, all research and development programs (in fact most proposed actions) have an inherent possibility that the results originally sought might not be attained--particularly on a fixed time schedule.

As used in this document, technical risk is defined as a quantification of the possibility that a proposed action will not produce the desired results in the time and monies allocated.

Statistics provides tools to quantify the probability of success for many actions including planning. In this application, a statement of $40 \%$ probability means four chances out of ten in attaining the desired result with the time and money allocated. By employing simultaneous investigations, the probability of success can be increased to any desired value. The important point is that if the probability is greater than zero, the result can be made to happen with suitable funding and time.

Classical examples of parallel (redundancy) approaches to important technical problems were employed in the near past. In the Manhattan project--whose principal objective was to develop a nuclear weapon to end World War II--parallel approaches were used to secure enriched uranium and plutonium and in the design of nuclear devices.

NASA used a multiplicity of parallel paths to assure that appropriate boosters, auxiliary stages, vehicles and even astronauts were available to place men on the moon. 
This R\&D plan uses a similar approach to assure that an acceptable nuclear waste disposal technology will be developed in a reasonable time schedule.

There are potential tradeoffs between scope and duration of R\&D work. If a particular disposal method is believed to have virtually certain probability of success, a crash effort focused on that option might be implemented, assuming human and fiscal resources can be committed. At the other extreme, a broad, lower-annual-level, and long-duration approach to the program might be selected. Alternatively, an approach intermediate to these extremes could be appropriate. The approach acutally taken will depend on present assessment of existing knowledge and judgmental extrapolation of that knowledge.

For the purposes of this plan, it was assumed that a reasonable time resource balance indicated a 20-year time span to commercial operation and that parallel efforts are necessary to assure a high probability of success in this time span.

\subsection{ASSESSMENT OF TECHNICAL RISK}

The present status of knowledge related to high-level and transuranic waste disposal R\&D programing can be briefly summarized as follows:

- Numerous disposal concepts that can potentially meet objectives on technical grounds have been identified. None has been developed and evaluated to the point where technical success is virtually certain, and none has been subjected to a full assessment of impacts of implementation.

- Demonstration that postdisposal phenomena cannot compromise longrange safety is crucial to technical success. At present, most R\&D sectors within this program are still planned for gathering data needed to make such assessments; evaluation methodology to use these data also requires development. 
- Despite lack of full-range data and assessment, technical judgment indicates that several geologic media have reasonably high probability of providing acceptable disposal.

The judgment that several geologic media can potentially meet the objectives of this program is based on the expertise of many disciplines and the results of many prior research programs. In brief, these prior studies have confirmed the long-term stability of the geologic media slated for further investigation within this program. This program therefore is designed to provide detailed physical, design, and impact data on media and sites for those media assessed to potentially meet disposal needs.

One method used to estimate the scope and thus the schedule of this program was assessment of technical risk, i.e., the chance that the program will meet its objectives. This assessment can be made using probability theory based on the following:

- The probabilistic level of success desired, assumed to be $95 \%$ or $98 \%$.

- Program procedures, selected to be winnowing of options investigated in parallel at each level in a series of three steps: generic, sitespecific, and pilot plant.

- Estimated average probability that the options investigated at any one level will successfully pass to the next level in the series. values used were:

$30 \%$ or $40 \%$ that a generic concept wi11 survive definition of a generic system and site reconnaissance to be the subject of detailed site studies;

$60 \%$ that a site will become a pilot plant; and $80 \%$ that a pilot plant will produce an acceptable waste disposal operation. 
Results obtained on this basis are summarized below.

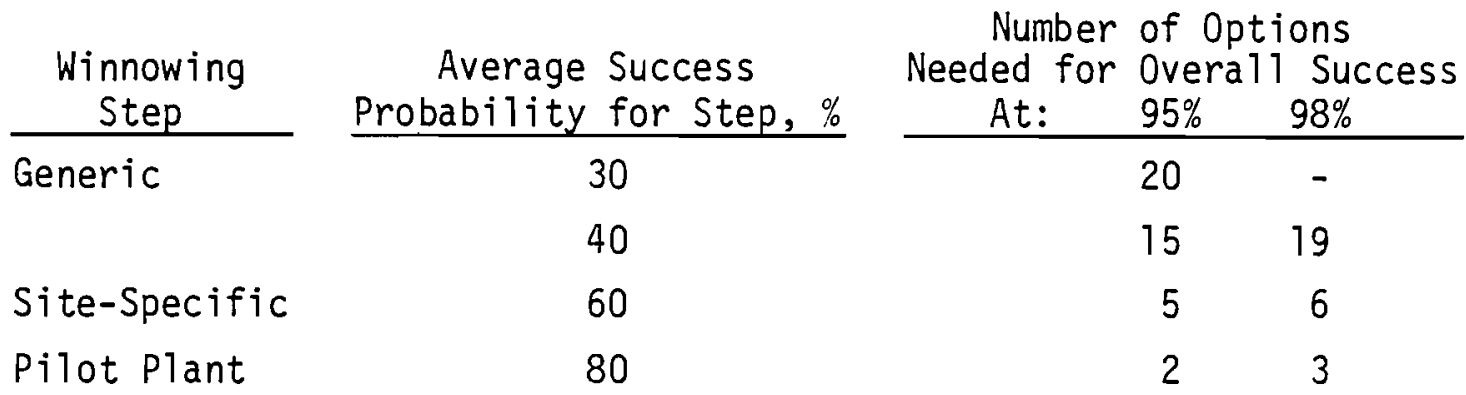

In the context of budget plans and decisions to be made in the near future, these results indicated that examination of the myriad generic disposal concepts to define 15 to 20 generic waste management systems should be planned. These can be expected to be winnowed at a later date to 5 or 6 detailed site development and characterization studies.

Several characteristics of binomial probabilities and possibilities for revision of program scope requirements can be noted.

- when, as in this program, successive winnowing steps are used, it is essential that the number of options available at the first step (i.e., the generic) be sufficient to meet objectives. The number of options required at the first step depends strongly on the success probability associated with this step. With present knowledge, assignment of a success probability higher than the $40 \%$ used here is considered unrealistic. Hence, at least 15 site-generic options should be investigated.

- Numbers of options to be investigated at the site-specific and pilot plant levels are, because of a "pinch effect" in the probability functions, relatively insensitive to the ultimate success criterion. For example, as the ultimate success criterion is increased from $95 \%$ to $98 \%$, the number of options required changes by only one. 
- Numbers of options required at the site-specific and the pilot plant levels are quite sensitive to the success probabilities for these levels. If these probabilities can be increased from the $60 \%$ and $80 \%$ values used here, the number of options to be investigated--and program costs--could be reduced. R\&D may significantiy increase the $60 \%$ and $80 \%$ values; if changes are warranted, they will be reflected in future statement of program plans. 


\subsection{SCHEDLLES AND MILESTONES}

The overall objective of this program is to develop acceptable methods for disposal of commercial high-level and transuranic wastes by 1997 . Program effort will be allocated to the following tasks and major milestones.

Figure 8.1 shows these activities as a function of program time. Annual and cumulative costs (constant $1975 \$$ ) are also shown.

\section{TASK 1: PLANNING}

The major function of this task is to support R\&D progress and decisions by preparing and periodically updating program plans.

Major milestones include:

- By January 1976, prepare a detailed work plan based on the schedule and activities cited in this plan.

To meet this milestone, appropriate teams will have to be assigned and funded for work during the remainder of $\mathrm{CY}-1975$.

- By January 1978, select and begin implementation of a schedule for periodic revision of overall program plans.

\section{TASK 2: RESEARCH AND DEVELOPMENT}

Work in this task will provide the basis for decisions on winnowing of options.

Major milestones include:

- Disposal Sites and Options

- Complete generic screening of continental and seabed disposal options by January 1977 . Decisions that will winnow the generic options (perhaps as many as 500) to the 15 to 20 systems with an estimated average $40 \%$ chance of success should have been made at this time. 

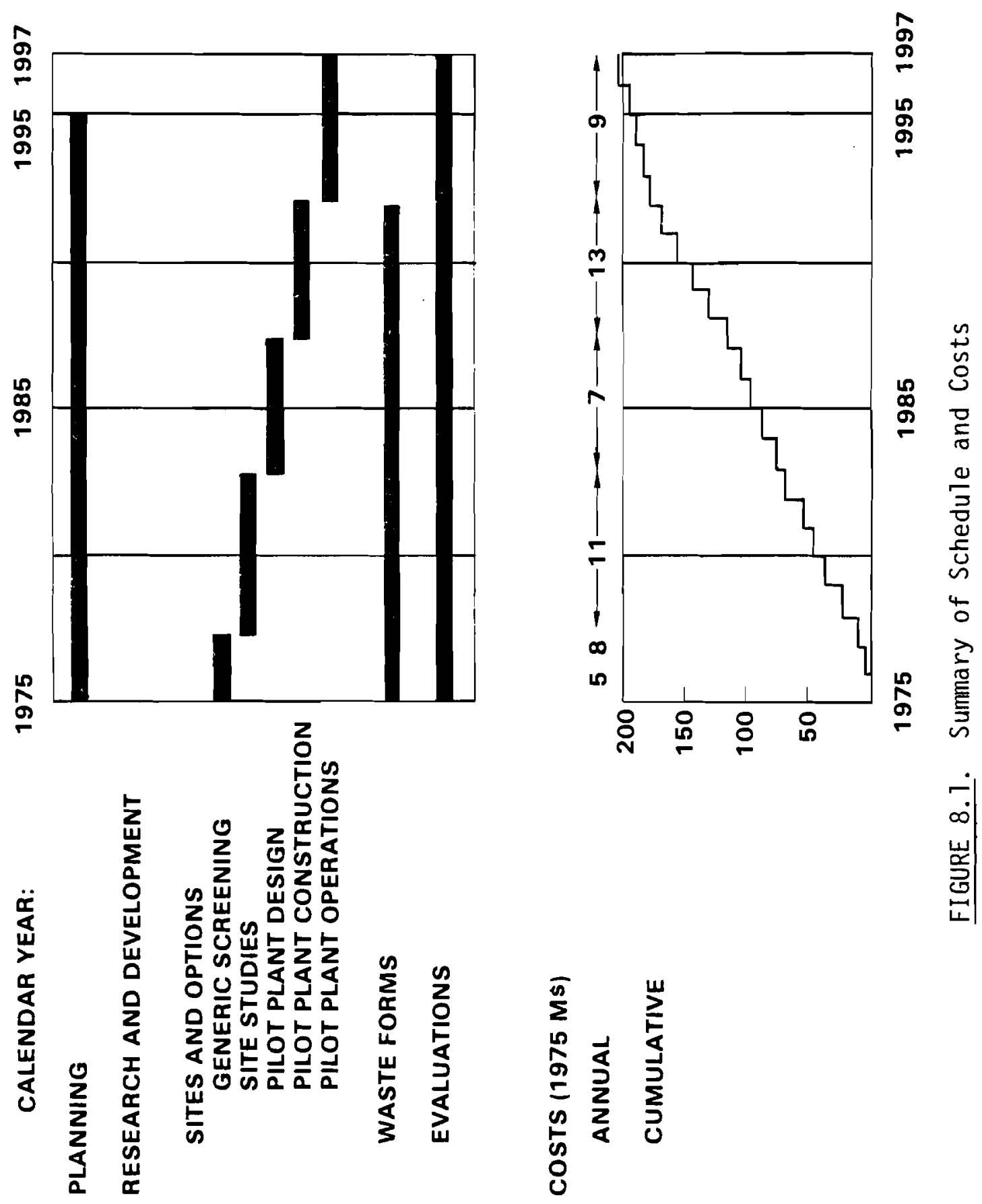

竞 
- Complete studies of the 15 to 20 generic systems by January of 1978. Decisions that will winnow these generic systems to the 5 site/systems that will receive detailed study (and should have an average probability of success of $60 \%$ ) should be completed by January 1978 .

- Complete detailed studies of the 5 site/systems by January 1983. Decisions to select the two pilot plants (which require an average probability of success of $80 \%$ ) should be completed at this time.

- Complete pilot plants design by January 1987.

- Complete pilot plants construction by January 1992.

- Complete pilot plants operation by January 1997.

- Waste Forms

Results from this sector must mesh with requirements of the disposal site work. Milestones can be expected to include:

- By January 1978, determine waste forms required for compatibility with the 5 sites that will be studied in detail.

- By 1987, complete determination of specifications for waste forms for the pilot plant sites.

- By 1992, have available the waste forms needed for pilot plant operations.

- Analysis and Evaluations

This work provides methodology for assessments that are the basis for decisions on winnowing of options. Major milestones include:

- By January 1976, complete assessment of existing methodologies and preparation of a plan for development of additional methodologies required.

- By January of 1977, complete development of methods needed for assessment of generic systems. 
- By January 1978, complete application of methodologies to generic assessments .

- By 1980, complete development of methods for assessment of the five specific sites.

- By 1982, complete application of methods to assessment of the five specific sites.

- By 1995, complete development and application of methods for assessment of pilot plant sites.

8.4 
No. of

Copies

\section{UNITED STATES}
A. A. Churm
DOE Chicago Patent Group
9800 South Cass Avenue
Argonne, IL 60439
C. R. Cooley
DOE Office of Waste Management
Washington, DC 20545
C. A. Heath
DOE Office of Waste Management Washington, DC 20545

\section{G. Derte1 \\ DOE Office of Waste Management Washinaton, DC 20545 \\ D. L. Vieth \\ DOE Office of Waste Management Washington, DC 20545}

R. D. Walton

DOE Office of Waste Management Washington, DC 20545

3. Neff

Program Manager

DOE

Columbus Program Office

Columbus, $\mathrm{OH} 43201$

\section{DOE Technical Information Center}

J. M. Batch

Battelle Project Management

Division

Battelle Memorial Institute

505 King Avenue

Columbus, $\mathrm{OH} 43201$

R. E. Heineman

Battelle Project Management Division

Batte 1le Memorial Institute 505 King Avenue

Columbus, $\mathrm{OH} 43201$ 
No. of

Copies

DOE-Richiand Operations Office

R. B. Goranson

B. D. Guilbeault

M. J. Shupe

D. J. Squires

M. J. Zamorski

H. E. Ransom

Cognizant RL Programs Coordinator

Pacific Northwest Laboratory

T. W. Ambrose

N. E. Carter

D. B. Cearlock

J. W. Finnigan

J. J. Fuquay

R. P. Marsha11

J. L. McElroy

R. E. Nightingale

D. E. Olesen

A. M. Platt

J. B. Burnham

5 Technical Information

2 Publishing Coordination 